\title{
Medicine Meets Thermal Spray Technology: A Review of Patents
}

\author{
J. Cizek ${ }^{1} \cdot$ J. Matejicek ${ }^{1}$
}

Submitted: 12 July 2018/in revised form: 10 October 2018/Published online: 4 December 2018

(C) ASM International 2018

\begin{abstract}
The patent literature concerning thermal spraying for biomedical applications is reviewed in this contribution. The patents were compiled from multiple databases search spanning the 2005-2018 period. For clarity and ease of reading, the results have been grouped into sections according to four individual material groups (apatites, titanium, oxide ceramics, other), with the secondary sorting criterion being related to the specific bioapplication areas (maxillofacial, orthopedic, methods). Lastly, the patents are grouped according to the selected thermal spray method within the individual subsections. In the paper, recent R\&D trends in this field are further identified and briefly commented.
\end{abstract}

Keywords applications · atmospheric plasma spray (APS) - biomaterials · cold spray · feedstock · HVOF . hydroxyapatite $\cdot$ processing $\cdot$ titanium $\cdot$ wire arc spray

\section{Introduction}

\subsection{Biomaterials}

Factors such as diseases, traumas, acute injuries, hereditary and genetic disorders, lifelong collection of toxicants and, most of all, aging, reduce the ability of a human body to replace defective or necrotic cells and repair damaged tissues. The history of medical sciences, the means of suppressing the impact of these negative factors, can be

\section{J. Matejicek}

jmatejic@ipp.cas.cz

1 Institute of Plasma Physics, The Czech Academy of Sciences, Prague, Czech Republic traced back to the beginnings of ancient civilizations. With the evolution of these sciences, aiding healing, correcting deformities or restoration of lost functions of various parts of human body have become progressively successful.

A special part of medical sciences is endeavors to partially or fully repair or replace defective tissues or body organs. The pioneering attempts in this area often resulted in unwanted consequences such as infections, embolism or tissue inflammation or necrosis that generally caused additional difficulties such as worsening of patient hardship, contiguous systems malfunctions, or, in the worst case, death.

The intensified public demands to develop this section of medical sciences evoked a rapid progress. It was not until 1860s when the advent of aseptic surgical techniques allowed an unprecedented boom in this area. After overcoming the primary problems with surgical methodology, the focus of research turned to a second milestone: the (bio)materials.

Initially, the empirical methodology of surgery allowed use of only a limited range of materials that were affordable and easy to acquire, process and manufacture. Wood, a natural high strength-to-weight-ratio composite, was used for limb prostheses and artificial teeth (Ref 1). Gold, a malleable and inert metal, was used in dentistry. Iron and brass were used to rejoin fractured bones, as well as original bone structures from other mammals (e.g., ivory). Glass was used as an eye replacement due to its cosmetic appearance. However, success in application of such traditional materials happened more by accident than by design, and these materials have become obsolete. The need to find suitable materials applicable to the needs of the human body became critical during the 1960s (Ref 2).

It was clear that the materials stood for the major hindrance in the area of human surgical operations. The 
approach of usage of traditional materials in surgery was reassessed, and novel types of materials were introduced. Surpassing the benefits and performance of the traditional materials, this new group of materials remains the source of intense research until today. Generally known as biomaterials, they provide the solution to many problems encountered in the area of medical sciences.

High biocompatibility (the ability of a material to perform with an appropriate host response in a specific application) is the first and most important condition required for present-day materials. Materials not meeting this criterion (materials with undesirable effects, secondary side effects) are no longer acceptable for medical and/or surgical purposes. Required levels of biocompatibility depend, among other factors, on the contact time between biomaterial and biological tissue, ranging from few seconds where the requirements need not to be strict (e.g., syringe needle, tongue depressor) to several decades where ultimate biocompatibility is an imperative (e.g., bone screws, total hip replacement).

The biocompatibility indicates the response of the host tissues when in contact with biomaterial. Furthermore, there is also a varying degree of interaction between the biomaterial and the tissue $(\operatorname{Ref} 2,3)$ :

- Bioinert materials are non-toxic and remain chemically stable even in long-term applications (years). Usually, a thin fibrous tissue surrounding the bioinert implant is formed as a tissue reaction. There are currently attempts to replace these first generation materials with proactive functioning materials. Stems of orthopedic implants or dental replacements are made of bioinert materials.

- Bioresorbable (biodegradable) materials are gradually resorbed by the body. Sometimes, the decay of a biomaterial is followed by a replacement with new tissues. The process usually ends when the biomaterial fully vanishes or is fully replaced by biological tissues. Controlled drug-delivery systems or vascular grafts and nerve guidance channels are made of bioresorbable materials.

- Bioactive materials actively elicit a specific biological response at the interface, usually resulting in a formation of a bond between the biomaterial and surrounding tissues. Bioactive materials are intermediate between bioresorbable and bioinert as they can retain both designs. Surface coatings of hard tissue implants or skin tissue implants are made of bioactive materials.

Bioactive and bioresorbable materials are referred to as second generation biomaterials. Third generation materials are bioactive materials with external activation of surrounding tissue cells and genes by adsorbed bone growthstimulating proteins such as bone morphogenetic proteins
(BMPs) or non-collagenous proteins such as osteocalcin. The activation is based on stimulation of specific cellular responses at a molecular level.

Assistance applications, i.e., aiding the biological system in performing its function, include dental repairs, caps, cavity fillers; cardiac pacemakers, cardiac assistive devices; contact lenses; scoliosis spine device; lung oxygenator machine; kidney dialysis machine; cosmetic surgery materials, augmentation mammoplasty, chin augmentation.

Common examples of repair applications (aiding the biological system as it physiologically restores its function) are fracture fixation devices; bone cement, bone plates; sutures; catheters, drains, shunts; burn dressings; artificial skin.

Removing the original diseased or damaged organ and substituting it with artificial biomaterials (replacement applications) are performed in case of artificial heart, heart valve (Ref 4); heart-lung machine; blood vessel replacement; cochlear replacement; eye lens replacement, glass eye; dentures, bridges; ligaments and tendons; intervertebral disks; artificial joints: hips, knees, shoulders, ankles, wrists, elbows. Some examples on the usage of materials for human bioapplications are illustrated in Fig. 1.

\subsection{Thermal Spraying}

Thermal spraying belongs to a group of processes in which metal or nonmetal materials are deposited in a molten or semi-molten state onto a prepared substrate to form a spray deposit (Ref 5). The material is inserted in various forms such as powders, suspensions, rods or wires, heated in a plasma jet or combustion flame and propelled toward the substrate surface (Ref 6). Depending on the technology, the high velocities of acting gases cause acceleration of the small particles of the material up to $1400 \mathrm{~m} / \mathrm{s}$ (Ref 7). Eventual heating can cause further increase in the particles kinetic energy and likely cause partial or full-scale melting of the particles (Ref 8). The immense kinetic energies stored in the particles account for the large amount of elastic and plastic deformation of the molten or semimolten particles during the process of its solidification at the surface. The solidified particles are called splats, and their size ranges from few micrometers to over $100 \mathrm{mi}$ crometers in diameter and about 1-20 $\mu \mathrm{m}$ in thickness. Synchronous movement of the thermal spray source relative to the substrate enables covering the substrate in individually deposited layers, each consisting of millions of the solidified splats. Thermally sprayed coatings often consist of several layers, and their typical thickness could vary from $5 \mu \mathrm{m}$ (usually a single layer coating) to $10 \mathrm{~mm}$.

The flexibility and versatility of thermal spray methods allowed them to enter a whole range of applications in the biomedical sector. Differing by the used technique, used 


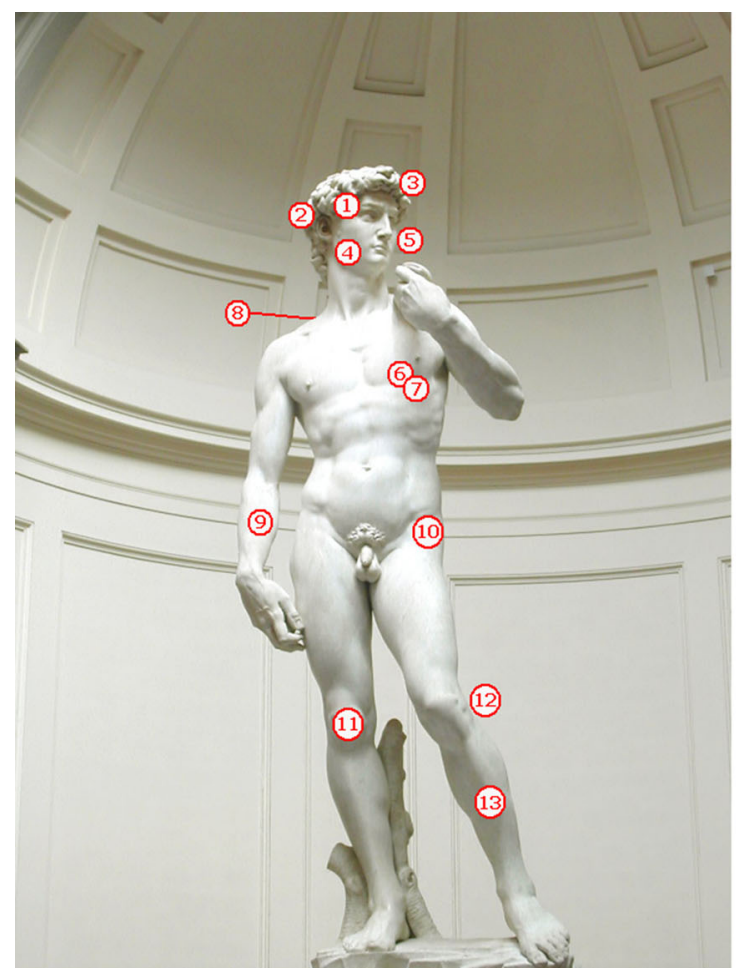

1. Ocular lenses

acrylates, silicone

2. Ear

silicone, $\mathrm{Al}_{2} \mathrm{O}_{3}, \mathrm{HA}$, Ti

3. Cranial

acrylic, 316L/SS, HA, TCP, Ti

4. Maxillofacial reconstruction

bioglass, $\mathrm{Al}_{2} \mathrm{O}_{3}, \mathrm{HA}, \mathrm{HA} / \mathrm{PLA}, \mathrm{TCP}, \mathrm{Ti}, \mathrm{Ti}-\mathrm{Al}-\mathrm{V}$

5. Dental

acrylic, bioglass, 316L/SS, $\mathrm{Al}_{2} \mathrm{O}_{3}, \mathrm{Au}, \mathrm{Co}-\mathrm{Cr}-\mathrm{Mo}, \mathrm{HA}, \mathrm{Ti}$

6. Heart, pacemakers

pyrolitic C, silicone, 316L/SS, Co-Cr-Mo, ePTFE, PET, PUR, Pt, Ti-Al-V

7. Blood vessels

ePTFE, PET

\section{Spinal}

Co-Cr-Mo, HA, Ti, UHMWPE

9. Degradable sutures

copolymers of PDO, PGA, PLA, PTMC

10. Load-bearing implants

$316 \mathrm{~L} / \mathrm{SS}, \mathrm{Al}_{2} \mathrm{O}_{3}$, Co-Cr-Mo, Ti, Ti-Al-V, UHMWPE, $\mathrm{ZrO}_{2}$

11. Prosthetic joints

acrylic, silicone, 316L/SS, Co-Cr-Mo, Ti, Ti-Al-V, UHMWPE

12. Ligaments, tendons

EPTFE, PET, PLA/C fibers, U HMWPE

13. Bone fixation

316L/SS, Co-Cr-Mo, PGA, PLA, PLA/HA, Ti, Ti-Al-V

Fig. 1 Illustration of the materials commonly used in human bioapplications. (Statue of David by Michelangelo Buonarroti from the collections of Galleria dell'Accademia di Firenze, Florence, Italy. Photographed by David Gaya, license: Wikimedia Commons)

materials for both substrates and coatings, they currently span the entire spectrum from assistance to repair to replacement applications.

\section{Patent Search}

Given the advantages of using thermal spray technologies in the biomedical sector, many patents in this area are filed annually. In this contribution, we present a digest of the patent literature (both granted patents and patent applications) going back to 2005. The literature search was done primarily through Web of Science-Derwent Innovation Index (Ref 9), with the help of European Patent OfficeEspacenet (Ref 10) and US Patent and Trademark Office databases (Ref 11), using keywords related to known thermal spray methods, materials, and applications in the biomedical sector. The sources included world patents (WIPO-World Intellectual Property Organization), as well as patents filed in the USA, European Union, China, Japan, Germany and the Czech Republic. No limitations were imposed on the country of origin. Some (relevant) patents may not have been included into this paper due to the non-uniform nature of the individual patent databases, and hence, the above search criteria used for data mining are stated herein.
The search focused on three topical groups-materials, application areas and methods. The patent claims varied from material preparation to novel processing methods (spraying, as well as pre- and post-treatment) to complete components (e.g., dental or hip implants). The role of thermal spraying ranged from a key part of the patent to one of possible alternatives.

Typical examples of the search terms according to the selected criteria included, e.g.,

- [(thermal or plasma or HVOF or cold) and spray*] and (hydroxyapatite or apatite or implant)

- [(thermal or plasma or HVOF or cold) and spray*] and (gahnite or baghdadite or calcium phosphate) and (implant or biomed*)

- [(thermal or plasma or HVOF or cold or flame or arc) and spray*] and (TiNb or Ti or Ti-Nb or TiNbTaZr or CoNiCr*) and (implant or biomed*)

The primary search according to these criteria returned 103 patents. Some of these documents were written in a way that the main patent claim was somewhat difficult to identify. Further, some of the patents were difficult to comprehend since the abstract was ambiguous when translated into English. In the following text (Sects. 3.13.4), the authors have tried to summarize the main patent 
claims and ideas in their own words for the benefit of the readers.

Figure 2 shows the distribution of the patent documents by the year of application and by the first inventor/assignee country. The time distribution shows a slight decrease in the years 2015-2017. This may be caused by some of the (pending) patents still being in the revision process by the respective offices. Considering the countries, the largest number of patents originated in the USA, followed by China, while all other countries had significantly lower numbers. This, again, has to be understood against the individual databases that were searched within the compilation of this document.

\section{Patents List}

There are several criteria for organizing the patents. In the text, the patents will first be sorted according to the materials used, with each materials group (apatites, titanium, oxides) dedicated to a separate Sub-sects. 3.1-3.3. Those patents, in which the sprayed material was not disclosed or was not important to the novelty idea, will be grouped in the last, separate Sect. 3.4. Each of these four sections is further sorted according to the criteria of applications (maxillofacial, orthopedic, innovative procedures). Finally, the last division of each section is done according to the used thermal spray methods, including post-processing of the coatings. A schematics of the paper distribution into the individual sections using the three criteria is shown in Fig. 3.

The innovative procedures enlisted in the applications (alongside maxillofacial and orthopedic) are those patents where the novelty is not directly related to a targeted application field, but rather the spraying procedure itself. Since the innovations concerning spraying methods/procedures are likely of higher interest to JTST readership, these are pinpointed with brief summary in Table 1. More detailed description is then provided in the corresponding sections of the main text. The methods/procedures generally involve spraying method modifications, special feedstock preparation, as well as pre- and post-treatments. Note that only novel approaches are presented in Table 1, omitting those documents that patented "general spraying" only.

\subsection{Calcium Phosphates, Hydroxyapatite}

\subsubsection{Maxillofacial}

Plasma Spraying Mandibular bone plate design improvement was patented in Ref 60, whereby two extension portions for defining bone facing surface were added. The portions are rotated along their length to better conform to the mandible bone. The extension portions are plasmasprayed to obtain hydroxyapatite, titanium or antibacterial coatings so as to improve physical or chemical properties to provide medications (Fig. 4).

A method providing an active growth of bone tissue into dental implants is covered in Ref 61. The invention refers to making an intraosseous dental implant in several steps involving sand-blasting by $\mathrm{Al}_{2} \mathrm{O}_{3}$ particles and plasma spray-based deposition of a system of biocompatible coatings containing mixed titanium/titanium hydride or hydroxyapatite powders. The sequence actually comprises two 50-100 $\mu \mathrm{m}$ layers of titanium or titanium hydride of
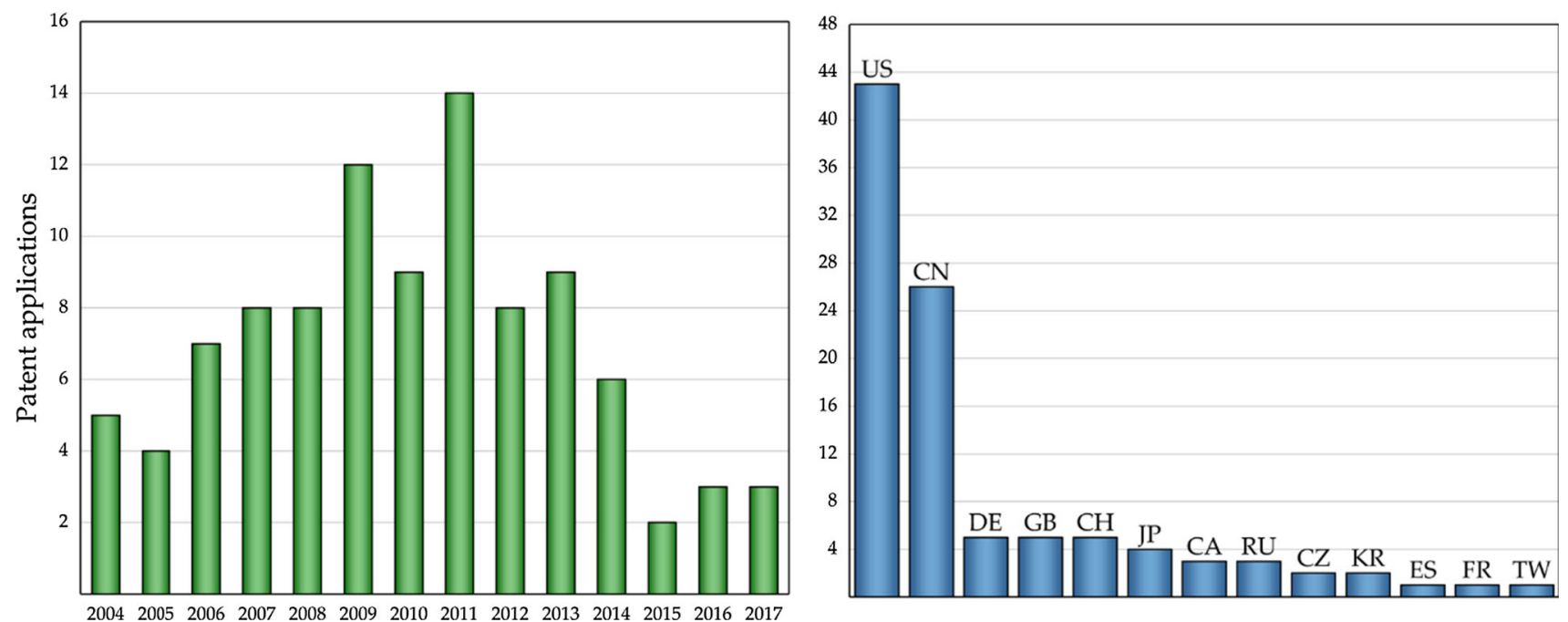

Fig. 2 Number of patent applications in individual years within 2004-2017 period (left), number of patent documents per the country of origin of the first inventor/assignee (right) 


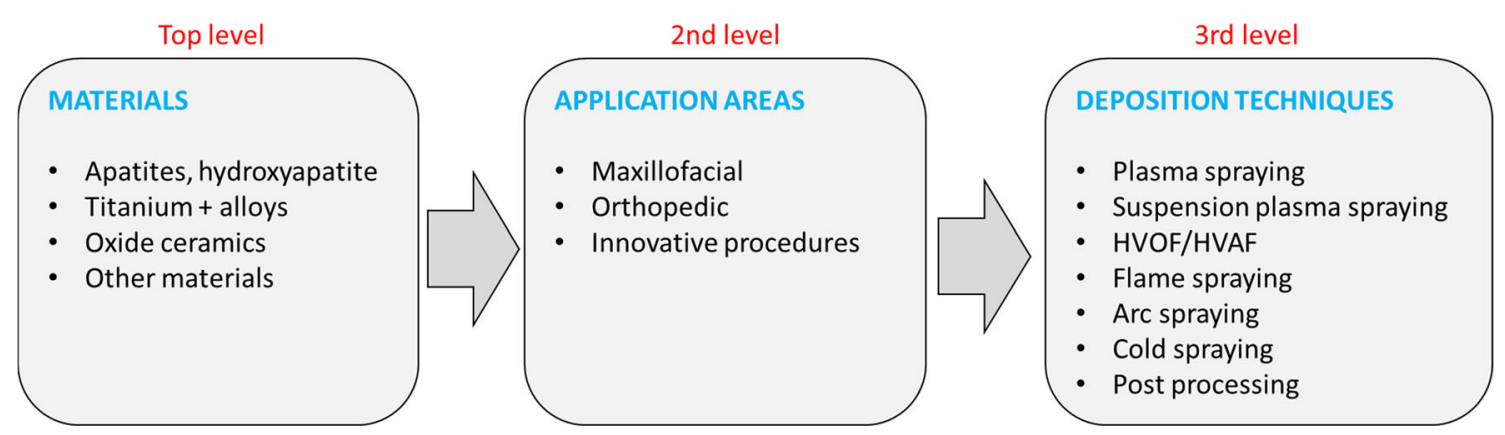

Fig. 3 Schematics of the paper organization into sections. Top-level subdivision is based on the materials groups. In the second-level subdivision, the third area contains patents focused on processing innovations. Third-level subdivision is made according to the specific

different porosities, followed by a $150-200-\mu \mathrm{m}$ layer of mixed titanium or titanium hydride and hydroxyapatite (20-40 wt.\%), and, finally, another 200-300 $\mu \mathrm{m}$ layer of pure hydroxyapatite. The whole system is covered by a metal film consisting of a ferric triad (iron, cobalt or nickel) of thickness 20-35 nm deposited by magnetron sputtering and a carbon $10 \mu \mathrm{m}$ nanocoating comprised of carbon nanotubes and carbon nanofibres of diameters 50-200 nm (Fig. 5).

A dental root implant useful in surgery process was patented in Ref 62. The component has a cylindrical core and a threaded part for fixation. The central part of the base is covered by a recrystallized, plasma-sprayed layer of a mixture of at least two different calcium phosphate materials. These have to have different melting temperatures. The economically manufactured dental implant supposedly has excellent attachment and quick gingival bonding, high durability and excellent stability and masticatory power for long periods of time.

\subsubsection{Orthopedic}

Plasma Spraying A component for installing artificial hip joints in a recess cover of the pelvis bone is presented in Ref 63 . The component is fabricated using surface treatments such as thermal spraying and subsequent roughening. The component (acetabular cup, actually) has an extra liner layer fitted in its inner side. An outer surface of the liner is provided with a taper-shaped surface. This is to make the two opposing surfaces to mutually contact reliably in a desired position, further suppressing any position shift of the liner, thereby suppressing damage rate of the liner in an effective manner (Fig. 6).

Novel implants with an open frame structure (apex, oblique and transverse support struts) retaining enough strength to prevent bending or failure are presented in Ref 64. The elongated implant body is made of metal and ceramic and is plasma spray-coated (from the outside) with deposition techniques. Cases where a generic term "thermal spraying" was used in the patent are assigned to plasma spraying sections in this paper

hydroxyapatite or titanium. It could be used, e.g., for fusion of a joint or joining two bone segments. The bony ingrowth into the scaffold is promoted and, by the openings, introduction of bone graft material is allowed through the implant. A curved variant of the implant is held by a pivoting arm and inserted without the aid of a guide pin by rotating the curved arm. The curved implant variant could be used, e.g., for fixation or fusion of sacroiliac joint for treatment of degenerative sacroiliitis, inflammatory sacroiliitis, iatrogenic instability of sacroiliac joint or traumatic fracture dislocation of pelvis (Fig. 7).

Authors of Ref 64 also filed a similar patent (Ref 65). In the document, a modular straight implant for fixation or fusion of two bone segments such as, e.g., sacroiliac joint is presented. The implant has an elongated open frame structure body comprising a set of apex struts aligned along the longitudinal axis. A set of support struts forms the matrix structure. The open frame structure allows to be packed with a bone graft material while providing enough strength to facilitate fusion of the joint or two bone segments without implant bending or failure. The main body is plasma spray-coated with hydroxyapatite or titanium.

Shorter variant of the femoral prosthesis (femoral neck, in fact) is presented in Ref 66. In the patent, the prosthesis is installed or fixed at the proximal end of the femoral bone in a total hip replacement procedure. The prosthesis loads the proximal end of the femur so as to prevent bone resorption, where a small portion of bone is only resected in the implantation process, thus ensuring that the prosthesis is bone sparing and allows an easy insertion procedure. The prosthesis has a fixation surface selected from a group of porous surface, porous layer, sintered beads, metallic foam or plasma-sprayed porous coating such as hydroxyapatite.

A four-component artificial intervertebral disk is presented in Ref 67. Its geometry allows six degrees of movement (flexion, extension, lateral bending, axial 
Table 1 Overview of patents focusing on the spraying methods/procedures. Abbreviations are explained in Sect. 5 at the end of the paper

\begin{tabular}{|c|c|c|}
\hline Section & Ref & Core of the patent \\
\hline \multirow[t]{22}{*}{3.1} & Ref 12 & PS sandwich coating $\left(\mathrm{TiO}_{2} / \mathrm{ZrO}_{2}+\mathrm{HA}+\mathrm{Ti}\right)$ for improved adhesion in implants \\
\hline & Ref 13 & Composite feedstock (HA core $+\mathrm{Ti}$ shell) and TS coatings \\
\hline & Ref 14 & FGM Ti + HA coating \\
\hline & Ref 15 & FGM Ti + HA coating \\
\hline & Ref 16 & HA feedstock with antimicrobial metal agent $(\mathrm{Ag} / \mathrm{Zn} / \mathrm{Cu})$ \\
\hline & Ref 17 & HA feedstock with antimicrobial $\mathrm{Ag}$ additive \\
\hline & Ref 18 & $\mathrm{HA}+$ povidone-iodine mixture for antibacterial properties \\
\hline & Ref 19 & $\mathrm{HA}+$ silver salt SPS coating \\
\hline & Ref 20 & Modified Ca-P feedstock - some $\mathrm{Ca}$ replaced by $\mathrm{Ag} / \mathrm{Cu} / \mathrm{Zn}$ by ion exchange \\
\hline & Ref 21 & SPS HA coating with enhanced porosity by pore-creating agent \\
\hline & Ref 22 & Co-spraying of HA and Ti by HVOF \\
\hline & Ref 23 & $\begin{array}{l}\text { Multilayer PS coating with porous outer layer }(\mathrm{HA}+\mathrm{Ti}) \text { and electrochemical integration layer of } \mathrm{Ti} \\
\text { alloy nanotubes }\end{array}$ \\
\hline & Ref 24 & Annealing of HA coating to improve crystallinity \\
\hline & Ref 25 & Electrolyte solution impregnation of HA coating to improve crystallinity \\
\hline & Ref 26 & Hydrothermal treatment of HA coating for nanostructure formation \\
\hline & Ref 27 & Micro-beam PS of HA \\
\hline & Ref 28 & $\mathrm{CS}$ of HA \\
\hline & Ref 29 and 30 & HA suspension feeding system \\
\hline & Ref 31 & SPS HA coating \\
\hline & Ref 32 & Surface nanocrystallization of PS HA \\
\hline & Ref 33 & Nanoscale HA powder \\
\hline & Ref 34 & SPS HA with collagen addition for improved bone formation \\
\hline \multirow[t]{8}{*}{3.2} & Ref 35 & $\mathrm{TS} \mathrm{Ti}+\mathrm{Ta}$ coating on non-metallic substrates \\
\hline & Ref 36 & Porous VPS Ti coating for bone ingrowth \\
\hline & Ref 37 & Diffusion bonding of CS $\mathrm{Ti}$ on $\mathrm{Cr}$ \\
\hline & Ref 38 & $\mathrm{CS} \mathrm{Ti}+\mathrm{Mg}$ coating, vacuum annealing for controlled porosity \\
\hline & Ref 39 & Surface patterning before PS Ti coating \\
\hline & Ref 40 & PS $\mathrm{Ti}+$ micro-arc oxidation + PS $\mathrm{CaTiSiO}_{5}$ \\
\hline & Ref 41 & Co-spraying of $\mathrm{Ti}$ with another powder for porosity control \\
\hline & Ref 42 & Multilayer of silicate glass, PS Ti and PS Ca-P \\
\hline \multirow[t]{7}{*}{3.3} & Ref 43 and 44 & PS $\mathrm{Al}_{2} \mathrm{O}_{3}+\mathrm{Ti}+\mathrm{TiO}_{2}$ FGM on orthopedic implants \\
\hline & Ref 45 & PS nano- $\mathrm{TiO}_{2}$ coating $+\mathrm{UV}$ radiation for bioactivation \\
\hline & Ref 46 & TS nanostructured $\mathrm{ZrO}_{2}, \mathrm{TiO}_{2}, \mathrm{Al}_{2} \mathrm{O}_{3}, \mathrm{HA}$ \\
\hline & Ref 47 & PS $\mathrm{TiO}_{2}+\mathrm{Nb}_{2} \mathrm{O}_{5}$ coating + surface activation \\
\hline & Ref 48 & Baghdadite feedstock synthesis \\
\hline & Ref 49 & PS $\mathrm{MgO}-\mathrm{SiO}_{2}$ coatings \\
\hline & Ref 50 & Production of refined $\mathrm{Cr}_{2} \mathrm{O}_{3}$ powder \\
\hline \multirow[t]{8}{*}{3.4} & Ref 51 & TS W coating for radio-opacity of medical devices + biocompatible coating \\
\hline & Ref 52 & CS spraying + EDM cutting of bioresorbable stents etc. \\
\hline & Ref 53 & TS porous Ti or Ta coatings + grit blasting of oxidized outer layers \\
\hline & Ref 54 & Fixture for concurrent coating of multiple implant components \\
\hline & Ref 55 & Open-pore biocompatible coating filled with resorbable material \\
\hline & Ref 56 and 57 & Pre-oxidation of $\mathrm{Zr}$ substrate $+\mathrm{PS} \mathrm{ZrO}_{2}$ coating \\
\hline & Ref 58 & PS or HVOF ceramic coating + diffusion bonding \\
\hline & Ref 59 & CS composite bonding layer between thermoplastic substrates and ceramic or metallic coatings \\
\hline
\end{tabular}



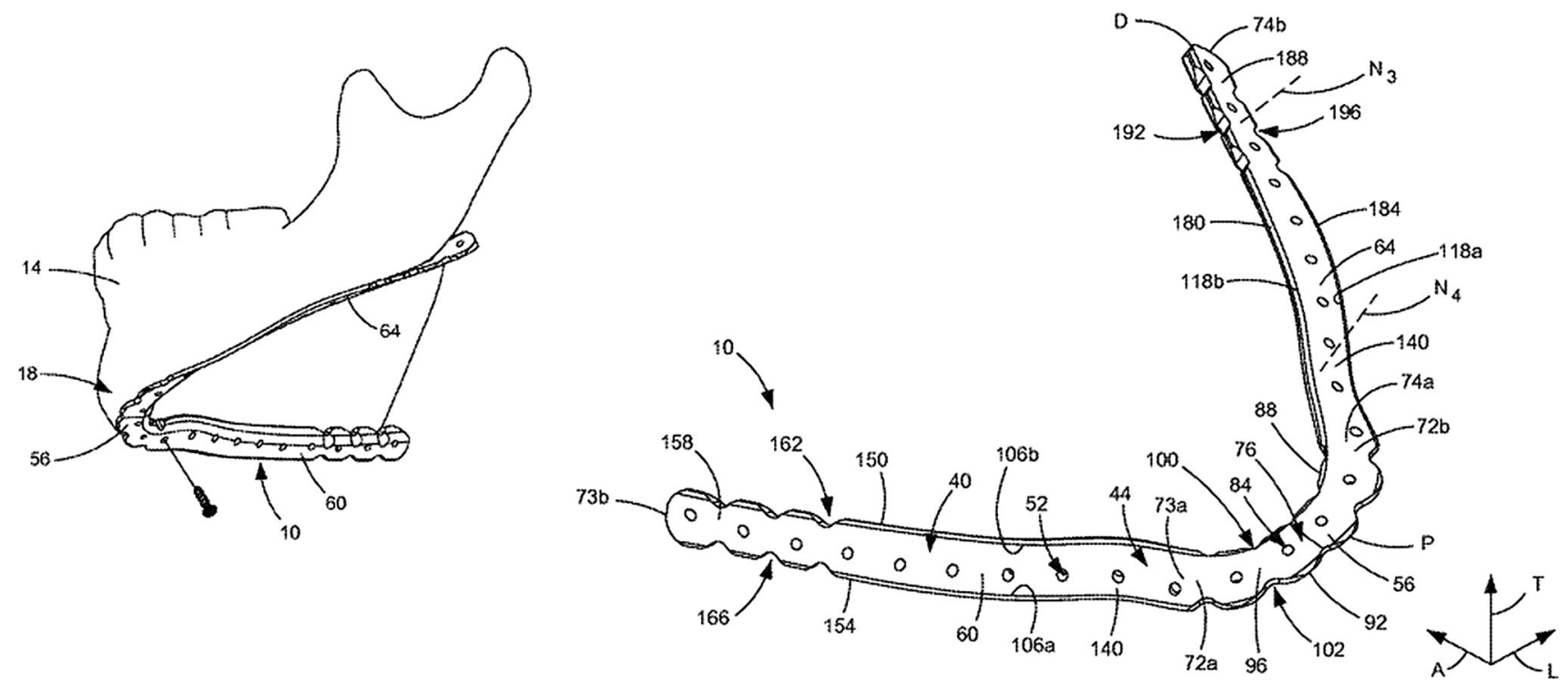

Fig. 4 An illustrative schematics compiled from the images provided in patent (Ref 60)
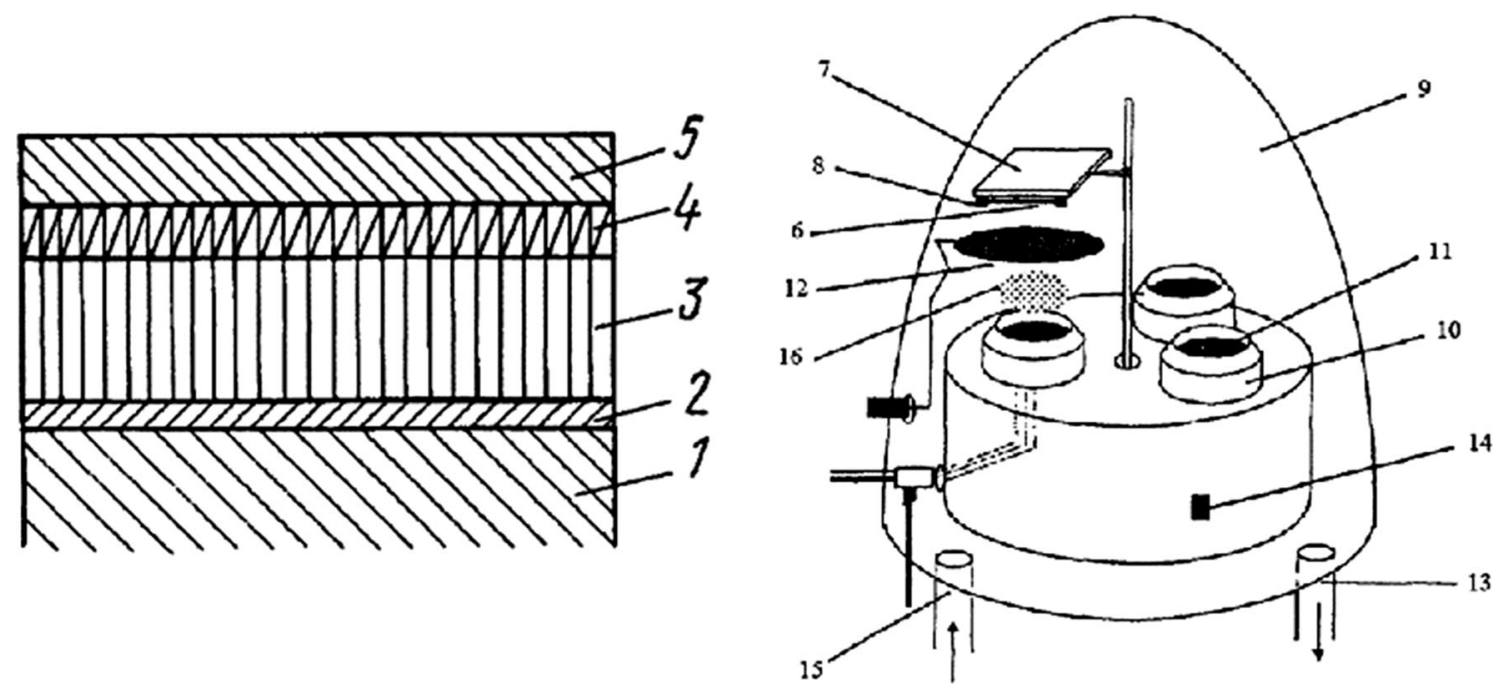

Fig. 5 An illustrative schematics compiled from the images provided in patent (Ref 61)

rotation, axial deflection and anterior/posterior translation), thus resulting in a more natural range of movement of the patient. The disk comprises a superior end plate and core, a flexible inferior core connected to its superior counterpart, an inferior end plate, and two PEEK inserts. The end plates comprise biconvex surfaces to provide an anatomical fit to the vertebral body and are covered by plasma-sprayed hydroxyapatite or titanium coatings. The disk is useful for replacing a diseased or damaged intervertebral disk during the spinal fusion procedure.

Two years later, the authors of Ref 67 filed a patent on a similar topic, artificial disk (Ref 68) for repairing and replacing intervertebral disks of a patient injured or damaged as a result of aging, trauma, fractures, degenerative disk disorder or a herniated disk. Designed for anterior or posterior procedures or minimally invasive surgeries, the disk also enables or restricts six degrees of movement and is compatible with a non-anterior surgical procedure. This time, shape memory alloys such as nitinol are used for the disk materials, providing increased durability. The superior and inferior end plates of the disk are treated with hydroxyapatite or titanium plasma-sprayed coating to encourage bony on-growth, thus improving strength and stability of connection to the underlying bone such as vertebral body. The rectangular-shaped prosthetic disk further provides a slim profile allowing easier insertion into the intervertebral space (Fig. 8).

Another orthopedic spine implant used, e.g., for the treatment of (lumbar) spinal stenosis is a device comprising of a couple of vertebral attachments, into which magnets 

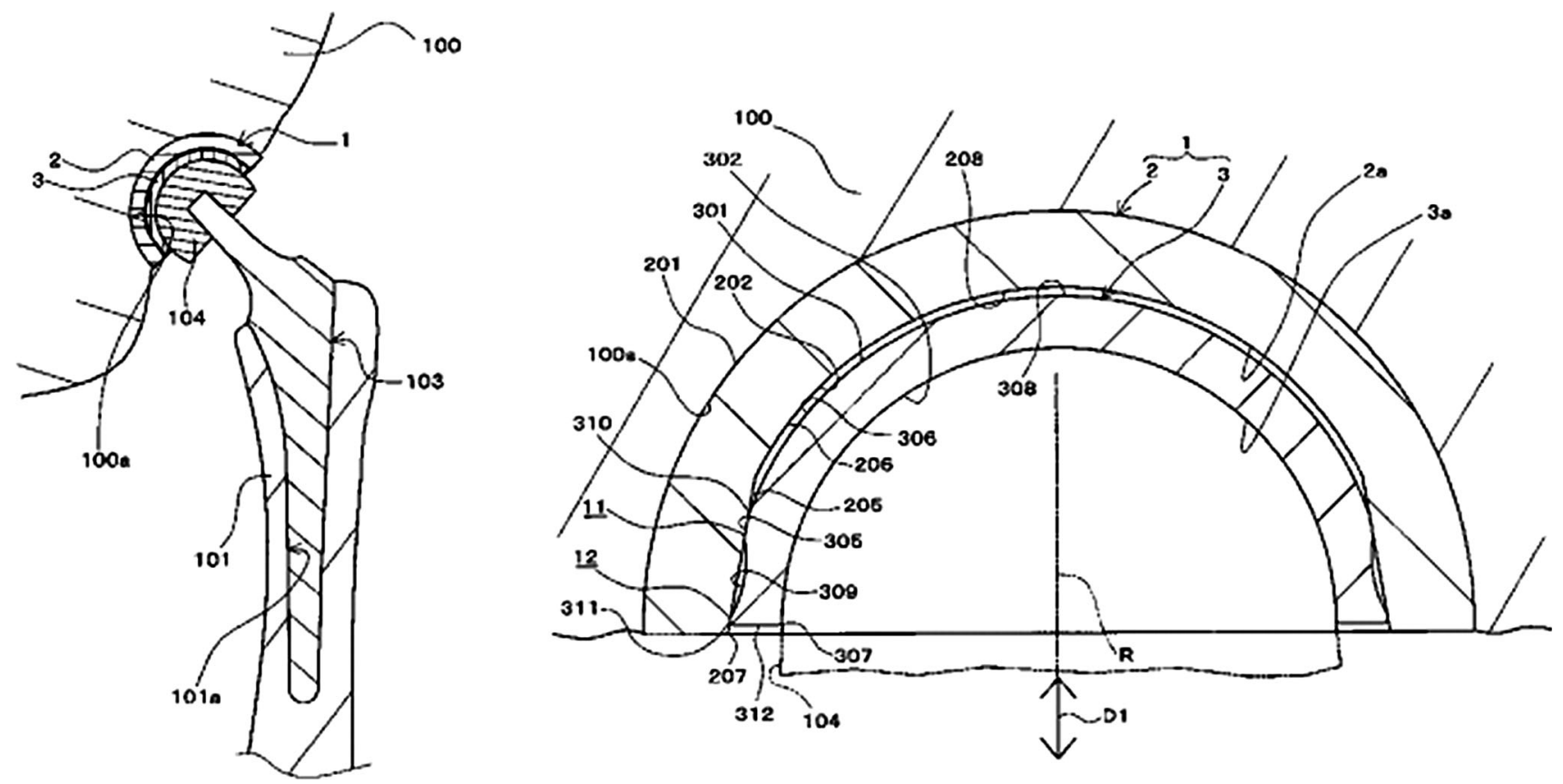

Fig. 6 An illustrative schematics compiled from the images provided in patent (Ref 63)
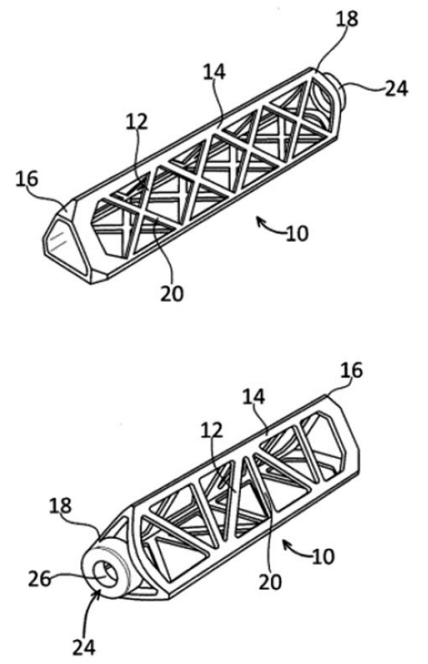
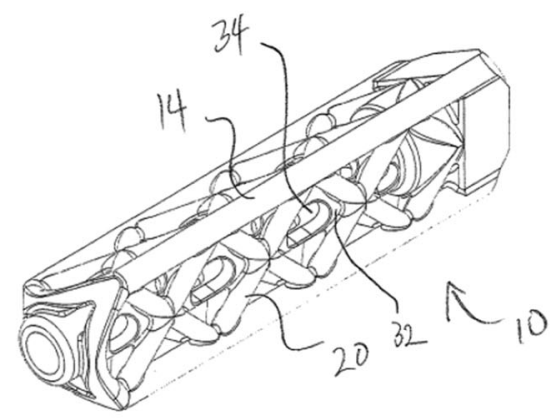
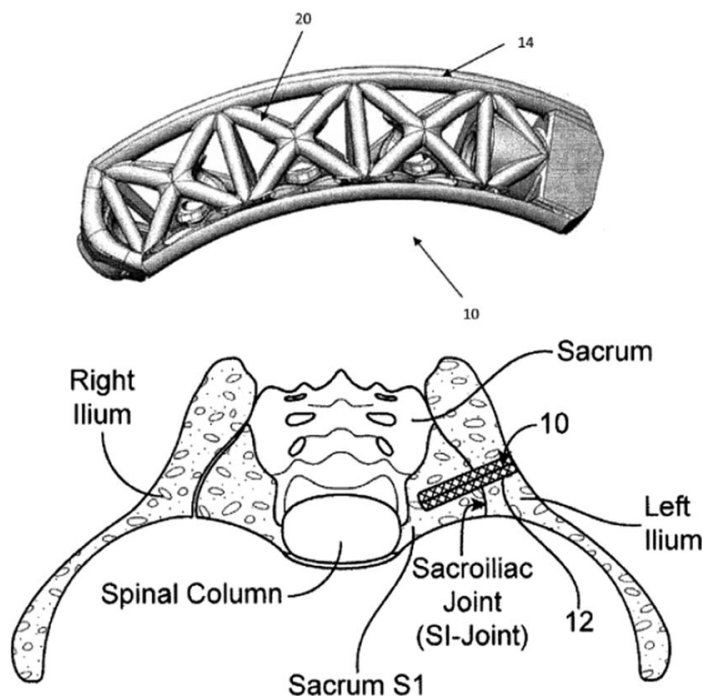

Fig. 7 An illustrative schematics compiled from the images provided in patent (Ref 64)

were incorporated (Ref 69). The attachments are either surface roughened or plasma-sprayed with hydroxyapatite or porous metallic coating to enhance their fixation to the spine. The magnets are made of nickel-plated, gold-coated neodymium grade N52. The device utilizes the magnets to balance in-plane and out-of-plane forces to provide an appropriate separation of the vertebral attachments during physiologic loading, thus reducing or eliminating the spinal stenosis and providing a constant relief on a nerve.

Another spinal plate for joining adjacent vertebrae to treat spinal deformities has a ridge connected to its bottom part that aids in attaching the plate to bone (Ref 70$)$. The plate is applied over multiple vertebrae so as to prevent the vertebrae from relative movement. The whole ridge is treated with a plasma-sprayed coating such as hydroxyapatite and titanium to encourage bony on-growth, thus stabilizing or strengthening the interface. The spinal plate's intended uses include treatment of a herniated disk, rheumatoid arthritis, infection and tumor.

A concept of a flexible acetabulum cup is presented in Ref 71. The plasma-sprayed hydroxyapatite-covered cup has an inner bearing surface with a partly spherical portion and also two independent, outwardly bowed arms spaced to define an opening in the cup rim. Through the cup 

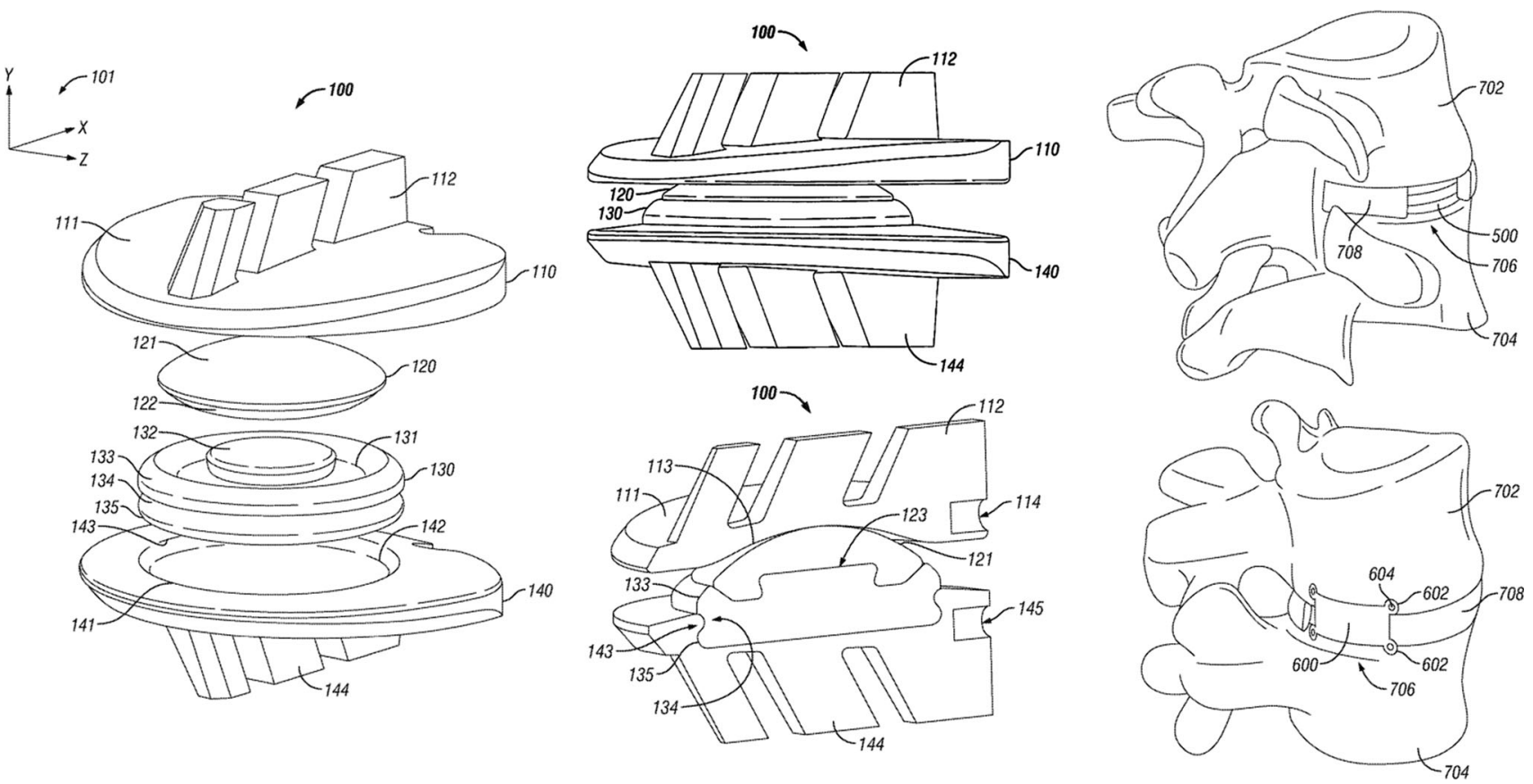

Fig. 8 An illustrative schematics compiled from the images provided in patent (Ref 68). Used with the permission of Globus Medical

geometry, the arms are prestressed toward each other upon insertion into the prepared acetabular socket. This arrangement prevents the polar area of contact from degenerating into a ring-type contact (Fig. 9).

A cost-effective artificial bone with high strength, excellent hardness, toughness and corrosion resistance is presented in patent (Ref 72 ). The bone comprises several layers of dissimilar properties: Its middle layer is made of a high-strength carbon fiber composite prepared by presoaking phenolic resin in unidirectional continuous fibers, while its outer layers comprise carbonized silicon layer, epoxy resin layer with silicon carbide, epoxy resin layer with plasma-sprayed hydroxyapatite, and, finally, hydroxyapatite layer provided with protein layer. The artificial bone is supposed to possess high bearing capacity, good tissue compatibility and good shaping performance. It is firm, durable, non-toxic, non-irritant and cost-effective.

A concept of hydroxyapatite-coated implant is filed in Ref 73. The hydroxyapatite coating is deposited from powder feedstock and has a rough surface, thereby enhancing the bone ingrowth. Importantly, it contains incorporated biocidal metal cations such as gold, platinum, palladium or silver. Through ion exchange, the implant then provides a controlled release of biocidal metal cations, thus preventing infection for extended time periods without causing toxic effects on body cells. The metallic implant is designated for surgical procedures such as, e.g., hip replacement or a prosthetic surgery such as, e.g., tibial prosthesis.

In 2013, the concept of the titanium implant from Ref 73) was further improved (Ref 74). In the updated version, anodizing was incorporated prior to the plasma deposition of hydroxyapatite coatings. Through the anodizing, hard oxide surface is created, containing numerous pits. Into the pits, biocidal silver ions are incorporated through immersion and a rough hydroxyapatite coating is then formed over the silver-containing oxide structure. After implantation, the silver ions can gradually leach through the ceramic coating into body fluids, effectively suppressing collagenous ingrowth without inhibiting the bone ingrowth. The implant is dedicated for surgical procedures such as replacement of a cancerous bone during prosthetic surgery or as a proximal tibia prosthesis.

A concept of titanium alloy-based orthopedic screw is patented in Ref 75 . The surface of the screw is covered by hydroxyapatite, titanium or silicon-hydroxyapatite coating. Using the method, the screw exhibits better anti-pulling force and rotary torque, thereby preventing bolt loosening. The screw is embedded into a bone to provide better early stability and ensure a growth of microporous bone tissue structure, widening the application range and better clinical application value.

An implantable, hydroxyapatite plasma spray-coated device that provides structural support for the skeletal system such as the spine is patented in Ref 12 . The device, made of PEEK, is dedicated for implantation to weightbearing joints as a bone support. It has a deployable securing mechanism connected to an implant body. The $45-100-\mu \mathrm{m}$ hydroxyapatite coating exhibited $\mathrm{Ca} / \mathrm{P}$ ratio from 1.65 to 1.76 and $>45 \%$ crystallinity, with $<5 \%$ other phases present. Its adhesion exceeded $15 \mathrm{MPa}$. The 

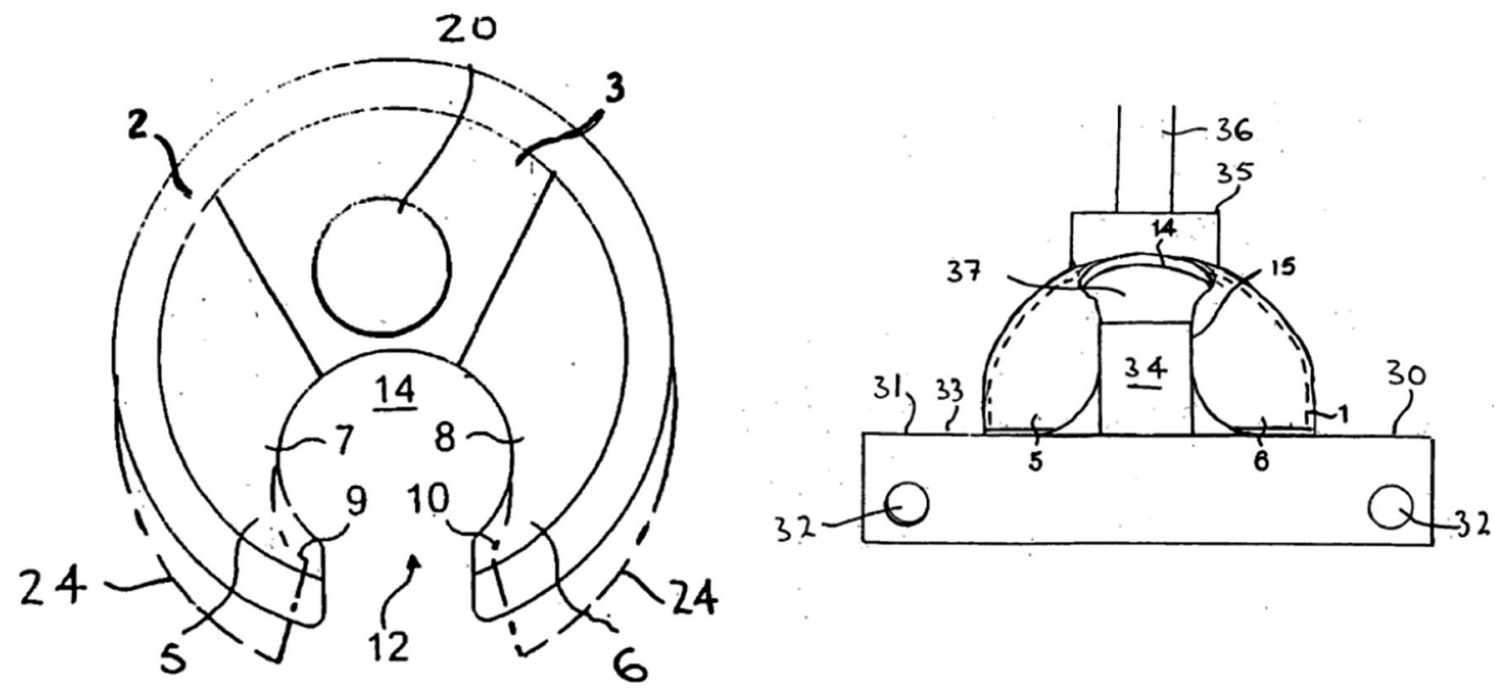

Fig. 9 An illustrative schematics compiled from the images provided in patent (Ref 71)

device is not fully specified in the document, and it is assumed that the patented novelty is the PEEK/HA combination, i.e., the device provides a bioactive coating of hydroxyapatite (HA) without altering the biocompatibility profile of the PEEK substrate. The device maintains the integrity of the hydroxyapatite (HA) coating and maximizes the strength of the implant.

\subsubsection{Innovative Procedures}

Plasma Spraying The method presented in patent (Ref 13) comprises plasma spraying of sandwich coatings: first, titanium dioxide or zirconium dioxide powder is deposited onto ceramic or polymer substrates to form an initial coating, followed by a further coating of hydroxyapatite (or metal). Within less than $10 \mathrm{~min}$, plasma spraying or electrodeposition of pure titanium onto the initial coating is further applied. The time interval between the depositions is critical to prevent formation of cracks or even spallation of the first oxide layer. The initial titania or zirconia layer is claimed to avoid problems associated with poor adhesion and is useful for implants in prosthetic or orthopedic applications (dental, spinal, craniofacial or maxillofacial).

Thermally sprayed implants (surgical, dental) using special powder feedstock with two-component particles are presented in Ref 14. In this method, PVD, CVD, electroplating or the dipping method are suggested for the production of powder particles comprised of a core material (hydroxyapatite) and an outer shell (titanium). Such feedstock can then be deposited using a range of methods, spanning vacuum plasma spraying, gas plasma spraying, combustion spraying or even cold spraying. Using these, a composite coating is formed on the implant surface, exhibiting negligible porosity and good bonding with no signs of cracks.

Similar in principle to patents (Ref 14,15$)$, titaniumhydroxyapatite gradient coatings for titanium alloy implant surface are described in Ref 16. The sandwiched material fabricated via low-pressure plasma spray technique consists of a titanium layer, two titanium and hydroxylapatite mixed layers (ratios of $40 / 60$ and 60/40) and finally a hydroxylapatite layer, arranged from inside to outside. As a result, a high stability and better bioactivity are reported. Such coating further exhibited reduced void content and an improved adhesion strength.

A method for multilayer plasma spraying of biologically active coatings onto a metal substrate of implants is patented in Ref 15 . The coatings in this patent are graded, starting with 1-2 layers of titanium, followed by a layer comprised of a mixture of titanium and hydroxyapatite, while the fourth layer is solely formed of hydroxyapatite only. The implants are subsequently placed into a container with silver nitrate solution (a concentration of $0.04 \%$ $\mathrm{AgNO}_{3}$ ) and exposed to $22 \mathrm{kHz}$ ultrasound for $35 \mathrm{~s}$ at an ultrasound intensity of $9.6 \mathrm{~W} / \mathrm{cm}^{2}$. Such invention should promote fast and reliable osseointegration of the implant that also possesses bactericidal effect.

Thermally sprayed implants using modified hydroxyapatite feedstock are presented in Ref 17. The HA powder contains antimicrobial metal agent such as silver, copper or zinc, prepared by ion exchange or solgel methods. The powder is then plasma-sprayed onto selected parts of the medical implants. The presented method eliminates the need for post-process heat treatment to further consolidate the coating or bond it to the substrate and eliminates the need to blend the HA powder with silver-containing powders to incorporate silver into the coating. Such coated 
implant reduces the risk of postoperative infection at the site of the implant.

Similar to the concept of Ref 17 , antimicrobial type of hydroxyapatite composite coating vacuum plasma-sprayed (10-30 kPa) on Ti6Al4V alloy is patented in Ref 18. The feedstock includes $1-5 \%$ metallic silver powder particles of 20-100 $\mu \mathrm{m}$ diameter as an antimicrobial additive ingredient, which is ball-milled into the original hydroxyapatite feedstock. Interestingly, the original hydroxyapatite particle diameter was smaller, $10-100 \mu \mathrm{m}$. The final composite coating exhibited excellent antimicrobial effect of more than $95 \%$ to Escherichia Coli, Pseudomonas aeruginosa and Staphylococcus aureus. The exosomatic cytotoxicity grade of such composite coating was zero, and the coating showed no cytotoxicity.

Another method of improving hydroxyapatite antibacterial properties is patented in Ref 19. By mixing of a hydroxyapatite powder and povidone iodine particles, the resulting vacuum plasma-sprayed coatings deposited on titanium and titanium alloy substrates retained 1-3\% iodine content. Such composite coating exhibited good antibacterial performance and antibacterial kill rate for Escherichia coli, Bacillus pyocyaneus and Staphylococcus aureus higher than $95 \%$. The composite coating retained good osseoconductivity, biocompatibility and showed no cytotoxicity.

Yet another bioactive coating doped with antibacterial content is patented in Ref 20. Specifically, the patent deals with hydroxyapatite coating containing silver ions (silver salt, in fact) on a surface of the substrate deposited by suspension plasma spraying. Misleading information on "the substrate material containing silver is added into the hydroxyapatite suspension" is provided in the text. The substrate materials from the patent involve titanium alloys, stainless steels, cobalt alloys, ceramic materials such as aluminum or cobalt oxides, and biomedical composites containing metal or ceramic. On these, an even coating is formed while avoiding releasing of the antibacterial ingredient.

Another antibacterial agent-containing coating was patented in Ref 21. The central part of the cementless implant (e.g., hip prosthesis for traumatology or orthopedics) has a plasma-sprayed calcium phosphate (e.g., hydroxylapatite) layer formed from powder feedstock and also $0.5-20 \mu \mathrm{m}$ antibacterial-active ingredients (silver, copper, zinc). In detail, the method suggests replacement of calcium ions in the crystal lattice of the calcium phosphate by the metal ions through ion exchange. This is supposedly achieved in the hydroxyapatite precipitation phase by addition of the respective metal salts. It is suggested that the utilization of hydroxylapatite and $\mathrm{Ag}$ enables a rapid growth of bone tissues and achieves reduction of operative and postoperative infection risks without affecting the process of bone growth.

In Ref 22, plasma-sprayed total replacement of femoral and acetabular components is presented. The cementless hip implant has a transition portion whose outer surface is provided with a protective porous surface layer (hydroxyapatite, titanium) aimed at collecting the potential debris from the acetabulum. The main body of the prosthesis is further equipped with an integrative layer of (5-200 nm long) nanotubes directly formed at its surface via electrochemical methods. The nanotubes are chemically identical to the implant material (titanium alloys such as Ti6Al4V, TiNbTa and TiNbZr) and fix the anchoring shaft in the bone tissue. The porous layer should further prevent debris, potentially originating in the acetabulum part, from contact with the surrounding tissues.

Suspension Plasma Spraying Porosity and pore size are critical in terms of osseointegration. In Ref 23, a simple and inexpensive method for preparation of plasma-sprayed hydroxyapatite coating with enhanced porosity on biomedical material such as titanium is presented. The principle of the preparation is usage of hydroxyapatite suspension, into which a pore-creating agent is added, stirred and subsequently plasma deposited. Specifically, ethanol, ammonium carbonate, ammonium bicarbonate, hydrogen peroxide or deionized water could be used as the agents, provided the suggested content of $16-45 \%$ is used. As a result, the porous hydroxyapatite coating should be helpful for oxygen and nutrient substance transfer, discharge of metabolism waste and biological activity elevation, thus providing a suitable microenvironment for cells and tissue regeneration.

In Ref 24, a system for feeding hydroxyapatite suspensions is patented. The system comprises a plasma spray torch, a suspension feed system, metal substrate and a substrate fixing rack. The novelty of the patent relies in using a simple, clamp-on system of the small-diameter feed nozzle (injection pipe) mounted to a fixing holder. The holder is easily attachable to the torch and, using that, the suspension could be injected directly into the high-temperature area of the plasma flame. This patent was filed in August 2011. Interestingly, an identical patent with a difference in only a few phrases was filed by the same authors in $2008(\operatorname{Ref} 25)$.

The same group of authors also filed a Chinese patent on preparation of hydroxyapatite coatings by suspension plasma spraying. The method involves fabrication of the hydroxyapatite suspension, its transfer into the jet and a formation of the hydroxyapatite biological activity coatings (Ref 26). The suspension fabrication was described in the text as a slow, drop-wise controlled reaction of diammonium phosphate and calcium nitrate. In the reaction, the $\mathrm{pH}$ 
was controlled to be $9-12$ at $30-90{ }^{\circ} \mathrm{C}$. After the reaction, "stewing for 5-15 min" is claimed, followed by aging for 24-48 h. The suspension feeding is provided either by using a compressed air flow, or a peristaltic pumping drain from a container with high-energy ultrasound wave vibration function. Injection into the plasma jet is done either using a small-angle atomizing nozzle in a radial direction or a small-diameter duct in a straight line jetting manner. As opposed to traditional powder spraying, the method claims to simplify the spraying process, save the sprayed material and energy, and produce coatings with uniform structure.

Preparation of nanoscale hydroxyapatite particles useful, e.g., as granular fill for direct incorporation into the hard tissues, as bone implantable materials, as tooth filling compounds, or as bone cements and dentifrices is patented in Ref 27. The method involves combining an amount of calcium ion source (calcium acetate) with phosphate ion source under essentially ambient conditions. The particles have the BET surface of $200-3000 \mathrm{~m}^{2} / \mathrm{g}$. Importantly, by reducing the aging time, Ostwald ripening of the particles is suppressed and their size distribution is maintained at 1-9 $\mathrm{nm}$. They are thus effective in drug delivery because they are more capable of penetrating the cellular wall (actually, also more readily processable by cells and tissues for regeneration and resorption) and carry a much higher surface area for adsorption of drug molecules. The range also allows the particles to be used intravenously as a drug therapy or for transdermal drug delivery. The particles can be either grown directly onto the metal surfaces without the need for any high-temperature processing, or can further be used in conventional processes such as solid-state sintering for polycrystalline ceramics, polymer-melt processing for polymer-ceramic composites or suspension plasma spraying for hydroxyapatite-coated titanium implants.

Calcium phosphate-based coatings fabricated by suspension phase plasma spraying were enhanced by the addition of collagen in Ref 28. The addition of collagen into the porous Ca-P coating (hydroxyapatite, tricalcium phosphate) structure is advantageous for the bone formation, as the phosphate-collagen composite coating could be loaded with growth factors or functional polypeptides for accelerating bone formation. The exact mechanism of collagen addition is not known from the patent. As a substrate, biomedical-grade titanium- or cobalt-based alloys or ceramics such as aluminum or zirconium oxides are suggested. Reportedly, the material is simple to prepare and has a low production cost, has better mechanical properties and significantly increases the success rate of implantable device, speeds up healing process, improves osteogenic activities of calcium phosphate bioactive coating, effectively accelerates cell adhesion, proliferation and differentiation, accelerates bone formation and early fixation of implants, improves performance for induction of the bone formation and accelerates early bone ingrowth.

HVOF Another innovation in two-component feedstock use for treatment of bone or joint implants is patented in Ref 29. Such treatment involves joint co-spraying of hydroxyapatite (5-97 wt.\%) and titanium (3-95 wt.\%) feedstock powders in at least one cycle by high-velocity oxy-fuel method or high-velocity flame spray method, thereby giving rise to $50-500 \mu \mathrm{m}$ coatings containing 0.01 5 wt. $\% \mathrm{CaTiO}_{3}$ formed by an in situ reaction.

Cold Spraying Based on two different methods, simple patents on fabrication of hydroxyapatite coatings using cold spraying (Ref 30) and microbeam plasma spraying (Ref 31) were filed in China. The former method is claimed to be used for tooth root and artificial joints by using "baked" $28-53 \mu \mathrm{m}$ hydroxyapatite powder (note that there is some uncertainty in the English translation) and its helium-argon deposition at rates of $0.05-0.50 \mathrm{~g} / \mathrm{min}$. Despite the feeding, high deposition efficiency is mentioned. The latter method involves spraying of dried hydroxyapatite powders onto a matrix of biomedical metal. The average powder diameters are also provided as $28-53 \mu \mathrm{m}$, while the transversal speed of the robot arm ("the speed of the gun pendulum" is mentioned in the original English translation) is given as $180-250 \mathrm{~mm} / \mathrm{s}$. Other parameters provided for the patent are standoff distance of $10-20 \mathrm{~mm}$ and $500-600{ }^{\circ} \mathrm{C}$ temperature and 2.5 3.0 MPa pressure of the nitrogen working gas. The method claims to be able to obtain hydroxyapatite coatings with high degree of crystallinity and good biological stability, while avoiding pyrolysis of HA and reducing loss of the hydroxyl groups. The final coating thickness is not provided in the text.

Post-Processing In Ref 32, a post-processing method for improving crystallinity of plasma spray-deposited hydroxyapatite coatings is introduced. The crystallization involves enclosing the hydroxyapatite-coated product in a sealed container, exhausting the container to a vacuum of $1 \times 10^{-1}$ to $1 \times 10^{-5} \mathrm{~Pa}$ and introducing saturated steam under $0.5-2 \mathrm{MPa}$ pressure (1-50 kg/h feed), followed by container hydrothermal recrystallization at $500-900{ }^{\circ} \mathrm{C}$ for 2-6 $\mathrm{h}$ and, finally, cooling. The efficient and stable method can be used for improving crystallinity of plasma-sprayed hydroxyapatite coating used for surgical implants.

Another post-treatment method of increasing the plasma-sprayed hydroxyapatite coatings crystallinity is patented in Ref 33. The procedure involves impregnation of the coatings in an $0.1-10 \mathrm{~mol} / \mathrm{L}$ electrolyte solution where all anions are hydroxide ions only. Anodic galvanostatic treatment follows, transforming any non-crystalline 
hydroxyapatite content due to the localized high temperature originating from the electrochemical reaction around the anode; the non-crystalline calcium phosphate in the coating electrochemically reacts with the hydroxide ions around the anode and converts into hydroxyapatite, leading to an increase in the coating stability. As an added benefit, the anodic treatment polarizes the coating and generates a large amount of negative charge, thereby increasing its biological activity. The method is claimed to have a short treatment time.

An efficient and economical method of post-processing plasma-sprayed HA coatings to obtain nanostructured material is patented in Ref 76. The method comprises vacuum plasma spray deposition of the coatings, followed by their hydrothermal treatment at $150-300{ }^{\circ} \mathrm{C}$, rinsing the treated hydroxyapatite coating and, finally, its drying. Thereby, nanostructured hydroxyapatite coating with improved biocompatibility, bioapplicability and bioactivity, superior osteoacusis effect, excellent protein and heavy metal adhesion, enhanced antibacterial performance and high density and crystallinity, prospectively useful as a bone replacement in orthopedics or dental field is obtained.

Surface nanocrystallization method for hydroxyapatite coating is presented in Ref 34 . In the method, a double hydroxyapatite coating is presented; the first layer of $30-60 \mu \mathrm{m}$ deposited via plasma spray process and the second layer of $20-40 \mu \mathrm{m}$ deposited by "bi-technology process," i.e., plasma spraying and a crystallizing treatment (unfortunately, no more details could be retrieved from the source). The coating reportedly exhibits excellent biological compatibility, comparatively quick osteogenesis speed, firm interface adhesion and a favorable long-term stability.

\subsection{Titanium}

\subsubsection{Orthopedic}

Plasma Spraying A modified hip implant with enhanced flexural capability and load-bearing qualities was patented in Ref 77. While the titanium plasma-sprayed (or sintered titanium wire) proximal end of the implant resembles that of the classical hip prosthesis, the distal portion was modified substantially to allow additional flexing: It has a cylindrical, constant diameter central aperture, where the wall thickness decreases progressively toward its end, including machined lateral cuts or slots on the outer surface, forming a continuous helix (Fig. 10). The selection of the slot geometry was made to prevent metal-to-metal contact on the adjacent surfaces during flexure that would eventually lead to formation of wear debris. The added flexibility should prevent bone tissue loss due to a lack of bone load-bearing capacity and reduce the stresses at the stem tip, thus preventing the postoperative thigh pain. Reportedly, such concept could be used for hip femoral head replacement, but also knee femoral and tibial component, humeral component for shoulder, elbow humeral component and bone plates as well as interlocking nails.

A concept of dual-taper lock modular prosthetic hip system for performing minimally invasive arthroplasty in hip (or shoulder) is presented in Ref 78. The system has a femoral neck implant component attached to a head, which is fitted within an acetabulum, allowing rotary movement. The outer acetabulum cup surface is designed to have a porous surface through plasma-sprayed titanium to grip the acetabulum, thus preventing slippage of the system during the insertion process. The system is further provided with a support sleeve made from cobaltchromium, ceramic and stainless steel to achieve sufficient strength (Fig. 11).

A dedicated orthopedic device assembly for concurrent placing of implantable spacers between superior and inferior vertebral bones was patented in Ref 79. The device has a non-implantable placement instrument holding the implantable spacers and a cavity that is configured to contain a bone-forming material (Fig. 12). The assembly is manufactured with a porous ingrowth surface, such as titanium wire mesh or plasma-sprayed titanium and tantalum, and provided with a bioactive coating made of tantalum and/or carbon nanotubes in order to promote bone ingrowth or establish a mineralized connection between the bone and the implant, thus reducing the chance for the implant loosening.

An orthopedic intervertebral implant to be used as an intervertebral disk space, e.g., in the lumbar, thoracic, cervical, sacral, coccygeal region, is provided in Ref 80. It contains a fixation assembly rotated about its transverse axis covered by plasma-sprayed titanium coating to improve growth of bone (Fig. 13). The vertebral fixation members are carried by the assembly and moved in the superior and inferior channels to extend the fixation members. The implant is then inserted into the intervertebral space to achieve restoration of height and fusion of fractured bone segments and to locate the intervertebral space anywhere along the spine as desired.

A ball-shaped component for prosthetic joint such as spine joint fabricated from sintered titanium carbide substrate, a sintered polycrystalline diamond surface formed on the substrate and bone attachment surface plasmasprayed from titanium is presented in patent $(\operatorname{Ref} 81)$. The substrate then comprises of $87.5 \mathrm{wt} . \% \mathrm{TiC}$ and $12.5 \mathrm{wt} . \%$ Ti. The component exhibits sufficient abrasion resistance and improved strength, toughness and compatibility without stress or cracking between the substrate and the diamond layer. 


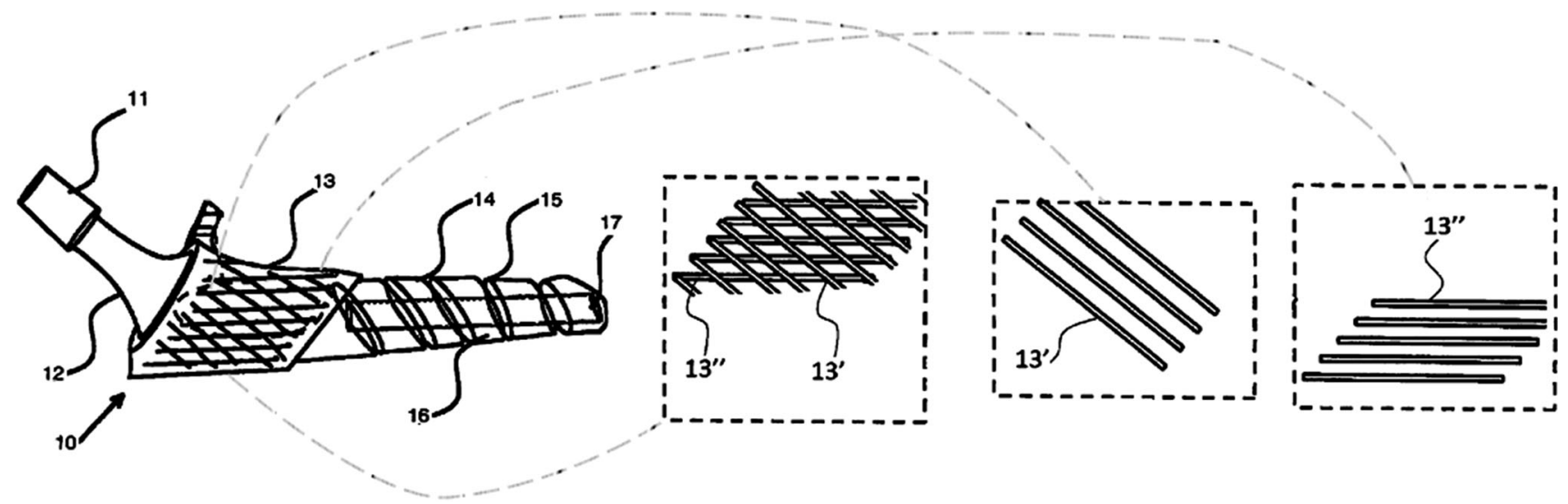

Fig. 10 An illustrative schematics compiled from the images provided in patent (Ref 77)
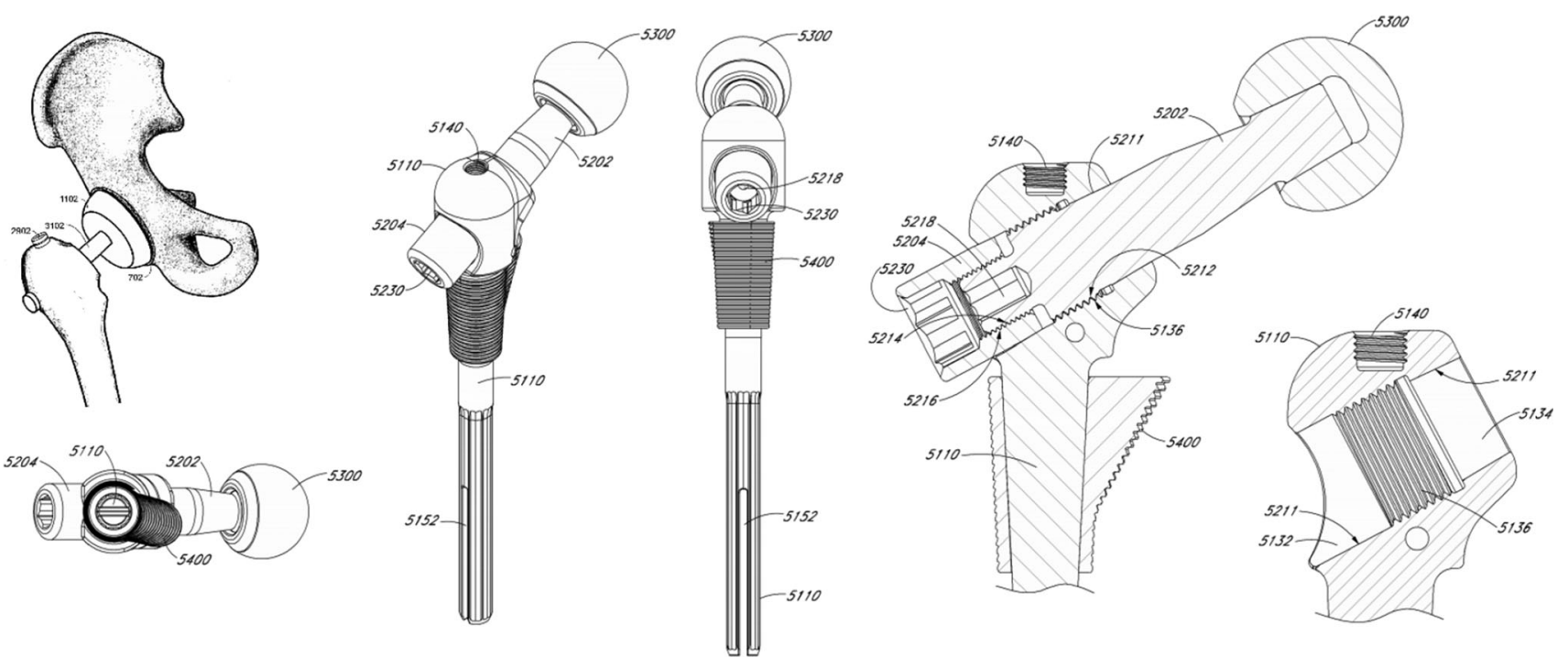

Fig. 11 An illustrative schematics compiled from the images provided in patent (Ref 78)
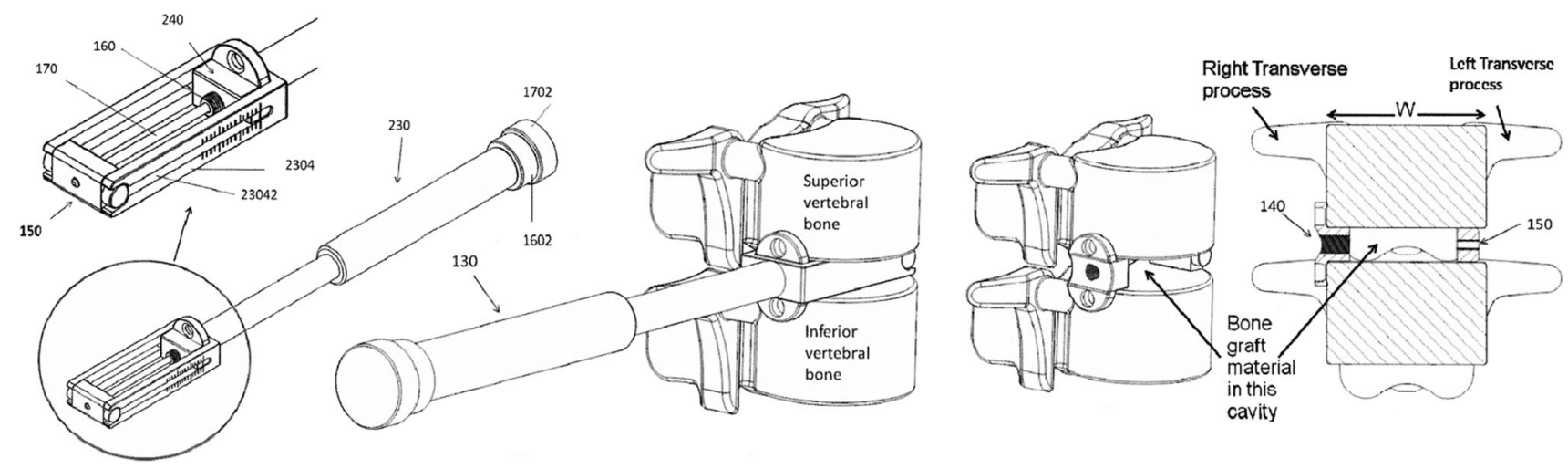

Fig. 12 An illustrative schematics compiled from the images provided in patent (Ref 79)

A combination of additive manufacturing, high-resolution computer tomography scanning and thermal spraying was presented in Ref 82. In the document, various stemless orthopedic implants to replace joint of shoulder are provided, starting with compaction of metallic powder into a component whose porous surface is replicated from a high-resolution scan of human bones. This is to promote ingrowth of tissue, along with a further, porous biological 

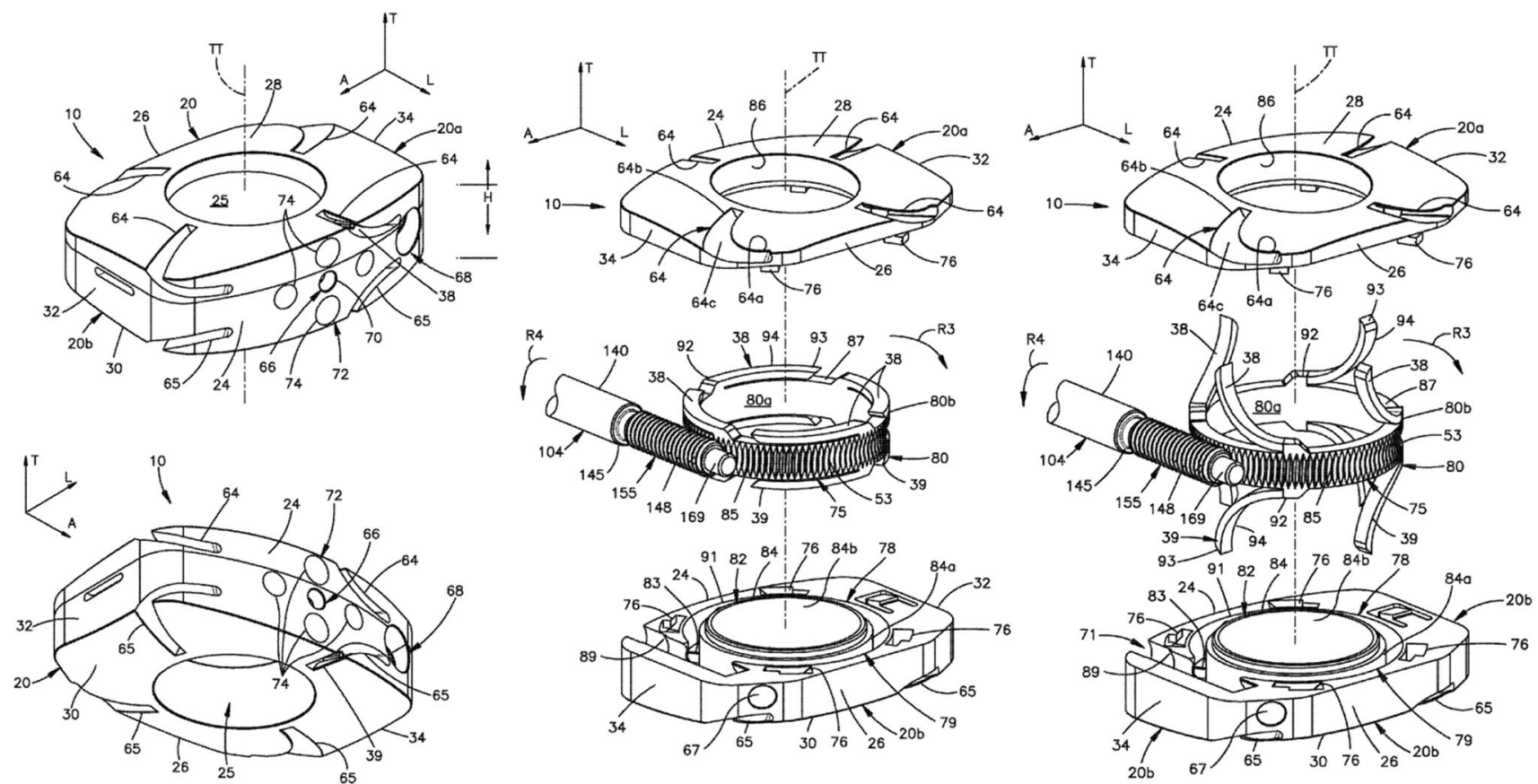

Fig. 13 An illustrative schematics compiled from the images provided in patent (Ref 80)

titanium surface coating created through plasma spraying. The implant uses a porous metal structure to mimic the trabecular architecture of the bone at a specific anatomical site where the implant is fixed. Generated by additive manufacturing technique, the time and cost of fabricating the implant should be reduced.

An important patent (Ref 83) was issued as late as 2008 , in which a technique of covering a surgical implant for bone repair applications by layers of titanium of two granularities $(20-50,60-160 \mu \mathrm{m})$ and $15-55 \mu \mathrm{m}$ hydroxyapatite is presented. The method for deposition was vacuum plasma spraying, and the obtained coatings thicknesses were 20-50, 70-150 and 30-100 $\mu \mathrm{m}$, respectively. The coatings are claimed to have high adhesion.

An osteotomy implant used for internal fixation or fusion of a bone fracture is patented in Ref 84. The (e.g., PEEK) wedge of the implant helps to stabilize and orient the bone and can be produced in various sizes and shapes to fit the surrounding bone without any portion of the wedge protruding externally. The component surfaces can be roughened to provide an early stability and to ensure intimate osseointegration between the bone and the wedge. The osteoconductive structure comprises a plasma-sprayed titanium coating thin enough $(2-500 \mu \mathrm{m})$ so that the component surface is transparent to imaging. Interestingly, the wedge core is deemed to have the same Young's modulus as bone (i.e., 3.6 GPa), thus preventing stress shielding of the bone.

A subcutaneous intramuscular mounting for a rigid transcutaneous implant is provided in Ref 35 . The device uses polyurethane material in the bone stump that comprises a distance spacer, a socket and a shoulder part (Fig. 14). The adaptable and replaceable polyurethane pipe is fitted to the socket and has an antibacterial outer wall, i.e., a thermally sprayed titanium-based coating containing silver and, optionally, calcium phosphate. This provides the polyurethane pipe with a high germ barrier and antibacterial effects. The method is deemed cost-effective. However, no details on the deposition of the coatings onto the plastic substrate are provided in the document.

\subsubsection{Innovative Procedures}

Plasma Spraying Initially claimed as an orthopedic implant, the patent (Ref 36) could be considered as a general concept for deposition of thermally sprayed titanium onto nonmetallic substrates of various implants such as the shoulder, elbow, spine, hip, knee or finger. Furthermore, the titanium deposits are doped (0.01-20 at.\%) with an x-ray-sensitive biocompatible metals such as tantalum. The atomic weight of such indicator metals is deliberately larger than that of titanium. The thermalsprayed surface layer can be economically manufactured with an increased spatial resolution and excellent biocompatible properties and ensures desired acceleration of the healing process.

The patent (Ref 37) uses vacuum plasma spraying to deposit porous titanium (or titanium + additives) coatings onto implant surfaces for ingrowth of vascularized bone tissue. The open-pore biocompatible surface coating 
Fig. 14 An illustrative schematics compiled from the images provided in patent (Ref 35)

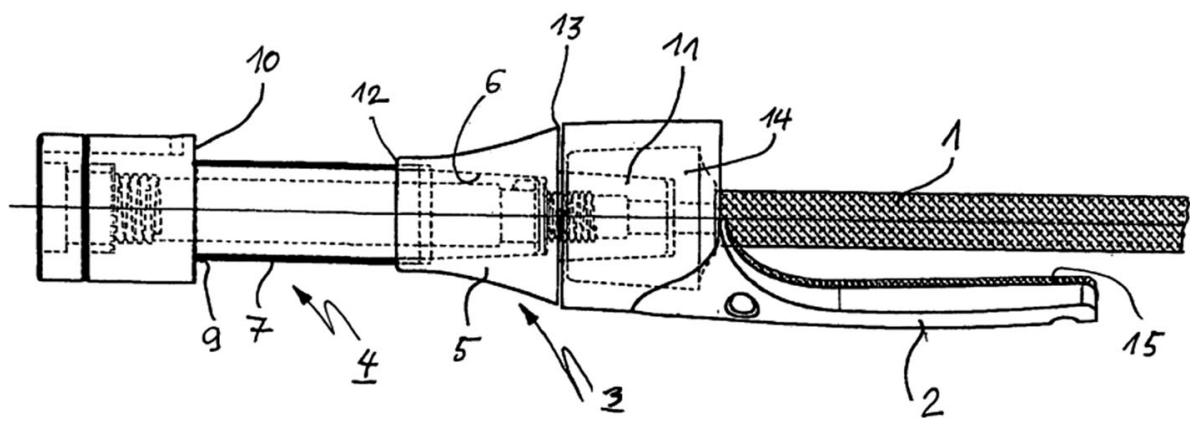

comprises a coherent pore network and has a defined surface area of at least $0.06 \mu \mathrm{m} / \mu \mathrm{m}^{2}$ (edge length per unit area). These could be used in, for example, hip joint shafts or sockets, the femur or tibial components of a knee joint replacement, a component of a shoulder, elbow, toe or finger joint replacement, a lumbar vertebral fusion component, a component of an intervertebral disk replacement or a transgingival and orthodontic or dental implants.

Arc plasma spray method was patented for production of titanium coatings onto implant surfaces in Ref 38 . The surface of the implant is further patterned through usage of template ("stencil") prior to arc spraying of $\sim 20-50 \mu \mathrm{m}$ titanium powder. Thereby, the patterned hard tissue replacement material is manufactured efficiently with rapid early response and long-term stability.

A graded coating consisting of porous titanium, sphene (titanite, $\mathrm{CaTiSiO}_{5}$ ) and titanosilicate ceramic deposited onto titanium-based implants surfaces was patented in Ref 39. Both coatings are deposited via plasma spraying. Before deposition of the sphene, micro-arc oxidation of the underlying surface is carried out. No further details could be derived from the document.

A somewhat broad patent was filed in Ref 40 . The idea of the patent is concurrent (plasma) spraying of titanium powder and another powder without the need for their mutual milling or pre-sintering. The patent does not provide detailed information, aside from the remark that "the second material at least partially melts in the plasma and binds to the first material." As substrate material for cementless fixation implants, titanium, zirconium, magnesium, tantalum or their alloys and cobalt-chromium alloys are mentioned, as well as a broad range of applications ranging from hip, knee, shoulder, spine, foot, toe, ankle or dental implants. The coating is presented as an open-porous structure providing micro-roughness for bone tissue stimulation, as well as macro-roughness for tissue/implant interlocking and an appropriate thickness for an integration zone. Reportedly, "an important advantage of the present method is a significant cost reduction for the production of an open-porous coating compared to the prior art."

A method for producing a structured coating on the surface of a femoral knee joint implant involves application of a thin hardening layer, abrasive processing and deposition of titanium via plasma spraying (Ref 41$)$. The implant is made of oxide ceramics, onto which a thin layer of silicate glass is applied and hardened by firing (silicate ceramic solder containing finely dispersed leucite, $\left.\mathrm{K}\left[\mathrm{AlSi}_{2} \mathrm{O}_{6}\right]\right)$. Then, the layer of titanium is applied onto the surface structure by plasma spray technology (or CVD). A calcium phosphate layer is then applied as the last layer. The method provides a durable connection between the implant and the surrounding tissue or bone cement, increases the speed of bone integration and allows quick replacement by newly formed bone tissue after the implantation.

Cold Spraying A concept of producing cast or forged $\mathrm{CoCr}$ based medical implants (ASTM F-75) covered by 5-3000 $\mu \mathrm{m}$ of titanium via cold spraying (gas pressures 2.56.5 MPa, gas temperatures up to $700{ }^{\circ} \mathrm{C}$ ) is presented in Ref 42. The interface of the two materials is further strengthened via diffusion bonding occurring during a subsequent hot isostatic pressing of the coated component $\left(480-1000{ }^{\circ} \mathrm{C}\right.$, 69-172 MPa, 1-5 h). The Ti-coated $\mathrm{CoCr}$ alloy medical implant has excellent resistance to corrosion and wear, as well as excellent fatigue life and biocompatibility.

A method of using two-powder feedstocks to produce thermally sprayed $\sim 500 \mu \mathrm{m}$ coatings of a given porosity ("aperture" in the original document) is presented in Ref 85 . In the invention, titanium feedstock powder is mixed with magnesium and these are then sprayed onto Ti-based substrates via cold spray. As a key, subsequent step, high-temperature vacuum sintering takes place to obtain porosity of a given size range $(30-200 \mu \mathrm{m})$ and content $(30-65 \%)$. Importantly, the porosity is uniform and easily adjustable, thereby changing the modulus of the coating from 30 to $50 \mathrm{GPa}$. The adhesion of the coating reaches $60 \mathrm{MPa}$ and can be used for production of artificial bone or tooth root.

\subsection{Oxide Ceramics}

\subsubsection{Maxillofacial}

Plasma Spraying Patent (Ref 86) provides information on the use of glasses and glass-based ceramics in dental and 
orthodontic applications. Manufacturing of such appliances (brackets, restoratives, replacements, inlays, onlays, veneers, crowns, bridges, implants, implant abutments, copings, anterior fillings, posterior fillings, cavity liners, sealants, dentures, posts and bridge frameworks) is achieved by thermal spraying of metal oxides onto substrates and, optionally, separating the coating from the substrates. The oxides provided in the patent comprise $>35$ wt. $\%$ aluminum oxide and a selection of metal oxides, such as boron oxide $\left(\mathrm{B}_{2} \mathrm{O}_{3}\right)$, germanium dioxide $\left(\mathrm{GeO}_{2}\right)$, phosphorus (III) oxide $\left(\mathrm{P}_{2} \mathrm{O}_{3}\right)$, silicon dioxide $\left(\mathrm{SiO}_{2}\right)$, tellurium dioxide $\left(\mathrm{TeO}_{2}\right)$, or vanadium oxide $\left(\mathrm{V}_{2} \mathrm{O}_{5}\right)$ and rare earth oxides such as yttrium oxide $\left(\mathrm{Y}_{2} \mathrm{O}_{3}\right)$, zirconium oxide $\left(\mathrm{ZrO}_{2}\right)$ and hafnium dioxide $\left(\mathrm{HfO}_{2}\right)$.

A patent on the use of nanostructured zirconia $\left(\mathrm{ZrO}_{2}\right)$ on the gingival part of a dental implant is provided in Ref 87 . The gingival shoulder part of the implant is tapered and threaded. Plasma spraying is employed for the uniform coating deposition, while titanium or titanium alloys are used as base materials. The preparation process of the substrate involves soaking in an alkaline environment at 60-80 ${ }^{\circ} \mathrm{C}$ for 5-8 min, washing using acetone, rinsing with distilled water, surface treating and spraying with ethylene oxide. Such plasma spray-coated nano zirconia implants reportedly exhibit an excellent external appearance, biocompatibility and mechanical strength. No further information covering the deposition of nano- $\mathrm{ZrO}_{2}$ could be derived from the patent.

Another design of a dental (tooth) implant is covered by patent (Ref 88). Made from ceramic materials such as zirconium or aluminum ceramics, or metal such as titanium or stainless steel, the implant body is inserted into a human jawbone, where the critical area is provided with a coating made from ceramic material. The rough surface coating is fabricated by using a plasma spray method, and the materials include zirconium oxide and, as a binder, silicon dioxide. That way, the implant possesses improved stability, while preventing damage and irritation of gum.

Thermal spray deposition to 6-50 $\mu \mathrm{m}$ thickness using a combination of aluminum oxide and zirconia is the core of patent (Ref 89). The coating is deposited on a metal (titanium, nickel titanium, Co30Cr5Mo vitalium or chrome cobalt) surface of, e.g., orthodontic arch-wire, partial denture clasp, dental implant, connector and abutment, whose surface is roughened and cleaned or etched before the deposition. The thermal spray process provides high bond strength and uniform thickness of the coating. The white ceramic surface coating itself further reduces and prevents growth of a biofilm.

Flame Spraying Antimicrobial dental implant such as artificial dental root, artificial tooth or artificial joint comprising of thermally sprayed brookite $\left(\mathrm{TiO}_{2}\right.$ polymorph) film on metal, ceramic or plastic substrates is provided in Ref 90. The coating is deposited via high-velocity flame spraying and exhibits superior antimicrobial activity in vivo as compared to the conventional antimicrobial products prepared using anatase-type titanium oxide as the active ingredient. Interestingly, the patent further suggests that the method can be applied for household products such as kitchen utensils, toilet products or even industrial products.

\subsubsection{Innovative Procedures}

Plasma Spraying A method of fabrication of acetabular shell cup through plasma spraying is detailed in two almost identical patents (Ref 43, 44). The method starts with a metallic mandrel that is sprayed with aluminum oxide first. After a suitable thickness is reached, the spray composition is gradually changed through a mixture of aluminum oxide, titanium and titanium oxide. The relative content of the aluminum oxide is decreased to the point where only a mixture of titanium and titanium oxide is sprayed. After the spraying process, the acetabular shell is extracted from the mandrel to form a freestanding coating part. Advantageously, the mandrel (fabricated via casting of slurry) is reusable due to its thermal stability. The methodology could be applied to obtain femoral, tibial or glenoid implants as well as tibial trays.

Another general method patent (Ref 45) covers the preparation of nanostructured titanium oxide coating layers with improved bioactivity. Preparing the bioactive layer includes deposition by atmospheric plasma spray method, washing and UV radiating for at least $12 \mathrm{~h}$ for biological activation. When in contact with body fluids, bone-like apatite is formed on the surface of the layer.

A method patented in 2006 (Ref 46) involves making of nanostructured biocompatible $1-550 \mu \mathrm{m}$ coating for promoting osteoblast growth on implants such as artificial hip joints under controlled spray parameters. The nanostructured coating is produced having enhanced mechanical properties and biocompatibility. Nanostructured agglomerated zirconia, titania, alumina or hydroxyapatite of the sizes from 0.1 to $200 \mu \mathrm{m}$ are covered in the document as the coating materials. As the methods, atmospheric plasma spray, HVOF, VPS, HVAF, low-pressure plasma spray (LPPS) and even high-frequency pulse detonation (HFPD) plus suspension variants of these are mentioned.

Preparing of titanium-niobium oxides composite coating provided with biological activity for surface activation treatment is patented in Ref 47 . Prior to their $30-50 \mathrm{~kW}$ atmospheric plasma spray deposition, the two powders $\left(\mathrm{TiO}_{2}, \mathrm{Nb}_{2} \mathrm{O}_{5}\right)$ are wet-mixed in alcohol bonding agent (540 wt.\%), ball-milled, dried, ground and sieved to a 25-105- $\mu \mathrm{m}$ fraction. After the coating formation, soaking 
in "energy body fluid" (no details provided, presumably $\mathrm{SBF}$ ) to induce bone-like apatite on the surface is used. The raw materials are easy to obtain, and the process is easy to control.

As a material prospectively competing with hydroxyapatite, plasma spraying of baghdadite $\left(\mathrm{Ca}_{3} \mathrm{Zr}\left[/ \mathrm{Si}_{2} \mathrm{O}_{7} / \mathrm{O}_{9}\right]\right)$ onto titanium alloys is patented in Ref 48 . Such coating has an adhesion exceeding $28 \mathrm{MPa}$, good bioactivity, low degradation rate in tri-hydrochloride buffer solution (possibly TRIS buffer), long-term stability and induces a formation of bone-like apatite (in simulated body fluid). The patent also includes a method of baghdadite powder synthesis via a high-temperature solid-phase reaction, its mixing with polyvinyl alcohol aqueous solution (510 wt.\%), drying the mixture and sieving the powder to 45-170 $\mu \mathrm{m}$.

Another method related patent involving use of oxide ceramics was filed in Ref 49 . This time, titanium or titanium alloy hard tissue replacements are covered with magnesium silicate coatings $\left(\mathrm{MgSiO}_{3}\right.$ or $\left.\mathrm{Mg}_{2} \mathrm{Si}_{2} \mathrm{O}_{4}\right)$ mixed with "a little glass phase" (undisclosed). Air plasma spraying technology is used for the deposition, with argon and hydrogen as arc plasma gases at $35-45 \mathrm{~L} / \mathrm{min}$ and 7-15 L/min flows, respectively, standoff distance 80-120 mm, spray current 500-700 A and powder feed rate of $12-18 \mathrm{~g} / \mathrm{min}$. Such coating should enable the implant to resist damage from physiological body fluids for a long time and facilitate its long-term stabilization.

The patent (Ref 50) describes a method for production of a refined chromium oxide powder. The method comprises spray drying of a raw chromium oxide feedstock, its fusing and crushing, followed by its acid and reduction washing. This results in a reduced amount of hexavalent chromium in the product $(<2 \mathrm{ppm})$, thereby achieving biocompatible threshold levels that can be used in thermal spraying of a $\mathrm{Cr}_{2} \mathrm{O}_{3}$ coating onto a medical implant. Packaging the refined chromium oxide powder to limit oxidation and absorption of moisture is also part of the patent.

\subsection{Other/Non-disclosed Materials}

\subsubsection{Maxillofacial}

Plasma Spraying Fabrication of dental components via several methods is patented in Ref 91. As the base material, beta-phase TiZrNbTa alloy with improved compressive strength, fatigue resistance, low modulus of elasticity and biocompatibility is manufactured from 50 to $250 \mu \mathrm{m}$ powder feedstock. The bulk material can be produced from the feedstock by several methods, all included in the patent document: thermal spraying of the powders onto a bed, selective laser melting, electron beam melting, three- dimensional printing, vacuum induction melting, vacuum arc reflow, melting plasma arc fusion, hot isostatic pressing or metal injection molding.

A method combining plasma spray deposition and sintering to produce dental implants is presented in Ref 92 . Using metal such as $\mathrm{Ni}, \mathrm{Cr}, \mathrm{Ti}, \mathrm{Pt}, \mathrm{Pd}, \mathrm{Cu}, \mathrm{Zn}, \mathrm{Au}$ and $\mathrm{Ag}$ as a substrate, a non-specified bioactive bond coat material is plasma-sprayed using argon, helium, nitrogen and hydrogen as plasma-forming gases first. Subsequently, a second ceramic layer (dental porcelain made of $\mathrm{SiO}_{2}$ quartz, feldspar and other oxides such as $\mathrm{ZrO}_{2}, \mathrm{Al}_{2} \mathrm{O}_{3}$ or even hydroxyapatite) is sintered from powders onto the surface of the plasma-deposited coating. Thereby, the adhesion strength between the metal cap and the dental porcelain layer is increased, and the metal caps are protected from the influence of metal ions in the human body, further reducing its oxidation. The dental implant can be precisely positioned on the gums, and the gum wear can be reduced to improve the patient comfort.

A tooth (or bone) implant plasma spray-coated with strontium-doped calcium polyphosphate (no further information) layer onto titanium substrate is patented in Ref 93 . With such coating, the implant exhibits enhanced biological activity and bone cell ingrowth and vascularization. It can further improve the implant and tissues interface compatibility and facilitate synostosis. For the deposition, $50-100 \mu \mathrm{m}$ powders are used and nitrogen as plasmaforming gas is suggested in the patent. The substrates are annealed at $700-800{ }^{\circ} \mathrm{C}$ prior to deposition.

\subsubsection{Orthopedic}

Plasma Spraying An expandable orthopedic implant for replacing hip joint is presented in Ref 94. The acetabular implant comprises two independent segments separated by a slit (Fig. 15). An expansion member placed between the segments can be adjusted to displace the portions relatively to each other, thus expanding the implant size. A screw passes through the implant to connect the implant to the acetabulum. The implant allows controlling the amount of torque applied to the expansion member, so that a proper press fit and interference with the surrounding bone is achieved. The implant is plasma-sprayed with a porous ingrowth material to improve strength and flexibility. Aside from the hip prosthesis, the concept could also be used for spine arthroplasty surgery, cranio-maxillofacial procedures, knee or shoulder arthroplasty, foot, ankle or hand extremity procedure.

A hollow, tubular threaded bone implant for fixation of sacroiliac joint is patented in Ref 95. The titanium implant body has a set of openings ("pores" in the original text) that do not extend through its entire thickness and a set of threads machined onto its exterior surface (Fig. 16). The 
former encourage tissue ingrowth into the implant, while the latter help inhibit loosening of the component in the bone. The implant includes a safety feature for preventing being driven too far into the bone. Importantly, the implant eliminates the need for autologous grafts, bone graft material, additional screws or rods, hollow modular anchorage screws, cannulated compression screws, cages, or other fixation screws, allowing less invasive surgical techniques. A porous plasma-sprayed coating with irregular surface supports a stable bone fixation/fusion.

Similar in concept to the patents (Ref 64,65$)$, a bone fixation implant for fusion of sacral-iliac joint is provided in Ref 96. The idea involves inserting the implant laterally through ilium, sacral-iliac joint and sacrum, stabilizing the adjacent bone segments (Fig. 17). Since the bony ingrowth region has a porous plasma-sprayed coating on its surface, a biomechanically rigorous fixation system is created to support a reliable fixation and acute weight-bearing capacity, and the pain generated from sacral-iliac joint is relieved in a minimally invasive manner.

A cementless implant with a patterned surface used, e.g., in knee replacement or tibial or femoral repairs is described in Ref 97. On the surface, tapered protrusions in a form of trapezoidal blades extending from the base are to mate with human bone. Additionally, each of the protrusions has a textured or porous surface to increase the area for bone growth provided by a thermally sprayed coating.

A multiple-step procedure for production of implants used for repair of the ends of bones at orthopedic joints is covered in patent (Ref 98). To match the Young's modulus of the human cortical bone, the implant is created from structurally strong isotropic graphite. It is then coated with hard, isotropic $>100 \mu \mathrm{m}$ pyrolytic carbon layer of a density $1.7-2.1 \mathrm{~g} / \mathrm{cm}^{3}$, hardness of at least $200 \mathrm{HV}$ and surface roughness of $R_{a}>2 \mu \mathrm{m}$, formed from aggregated 0.15$0.5 \mu \mathrm{m}$ carbon particles. Porosity of the layer is provided

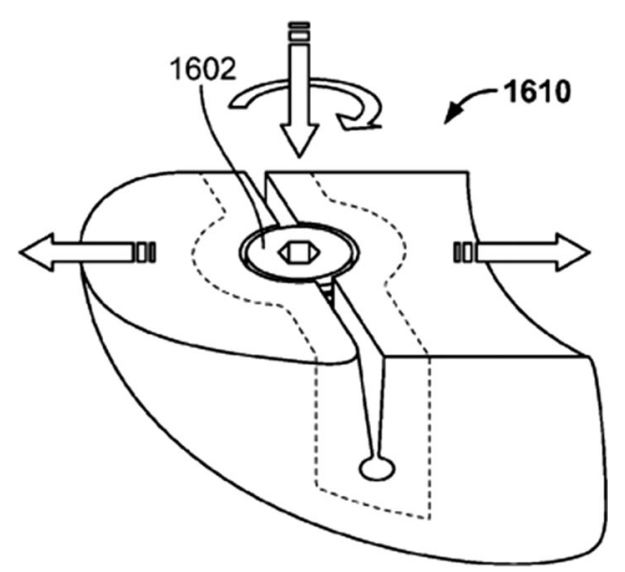

Fig. 15 An illustrative schematics compiled from the images provided in patent (Ref 94) as $2-10 \%$ with the pore sizes suggested at $0.05-0.1 \mu \mathrm{m}$. This layer is then polished and serves as a receiving surface for a $2-10-\mu \mathrm{m}$ metal coating deposited via PVD process. During the PVD, the metal penetrates into the pores to create a secure bond and smoothen the pyrocarbon surface. Lastly, plasma spraying of a $>25-\mu \mathrm{m}$ biocompatible metal layer onto a designated portion of the implant is carried out. The implant produced through this method should promote attachment to bones without the need for ancillary cement and exhibit high strength, wear resistance, resistance to cyclic fatigue, biocompatibility, and a modulus of elasticity similar to cortical bone.

A concept of an apparatus to provide coupling pads for an implant is presented in Ref 99. These are made of porous metal with suture accepting holes that help attaching the surrounding soft tissue to the implant. The area defined by the notched surface of the soft tissue coupling mechanism is filled with porous plasma-sprayed layer allowing vascularization/angiogenesis and nutrient delivery important for soft tissue ingrowth. Mechanically, the pads are attached to the implant through a locking mechanism such as threaded fastener, which prevents unwanted movement (Fig. 18). The complete implant is then implanted into a bone with the soft tissue attachment pads. The concept could be used for, e.g., shoulder arthroplasty.

\subsubsection{Innovative Procedures}

Plasma Spraying A unique solution for sensitive medical devices such as pacemakers, defibrillators, nerve stimulators, hearing aids or drug pumps with incorporated radioopaque and biocompatible coatings is patented in Ref 51 . In the method, a radiation shield made of tungsten is integrated with an implantable medical device by thermal spraying, partially surrounding its electronic circuitry (Fig. 19). Subsequently, the device is provided with a biocompatible coating defining at least a portion of its outside surface (bioglass, hydroxyapatite, titanium, titanium alloys, alpha-alumina, stabilized zirconia, or apatite ceramics). In an example where the device is a nuclide source for destroying malignant cells, such arrangement allows prospective radiation to be directed only to the tissue to be treated.

A rather universal patent filed in 2017 (Ref 100) deals with the method of thermal spraying (atmospheric plasma and vacuum plasma) deposition of ceramic layers onto surfaces of components for functionalization of medical devices, preferably prostheses and implants. The patent lists the following materials: $\mathrm{Al}_{2} \mathrm{O}_{3}, \mathrm{ZrO}_{2}, \mathrm{SiO}_{2}$, bioglass, TCP and hydroxyapatite. However, no further details could be acquired from the documentation.

A method of deposition of non-oxidized metallic (e.g., titanium, tantalum) coatings onto medical devices such as 
Fig. 16 An illustrative schematics compiled from the images provided in patent (Ref 95)
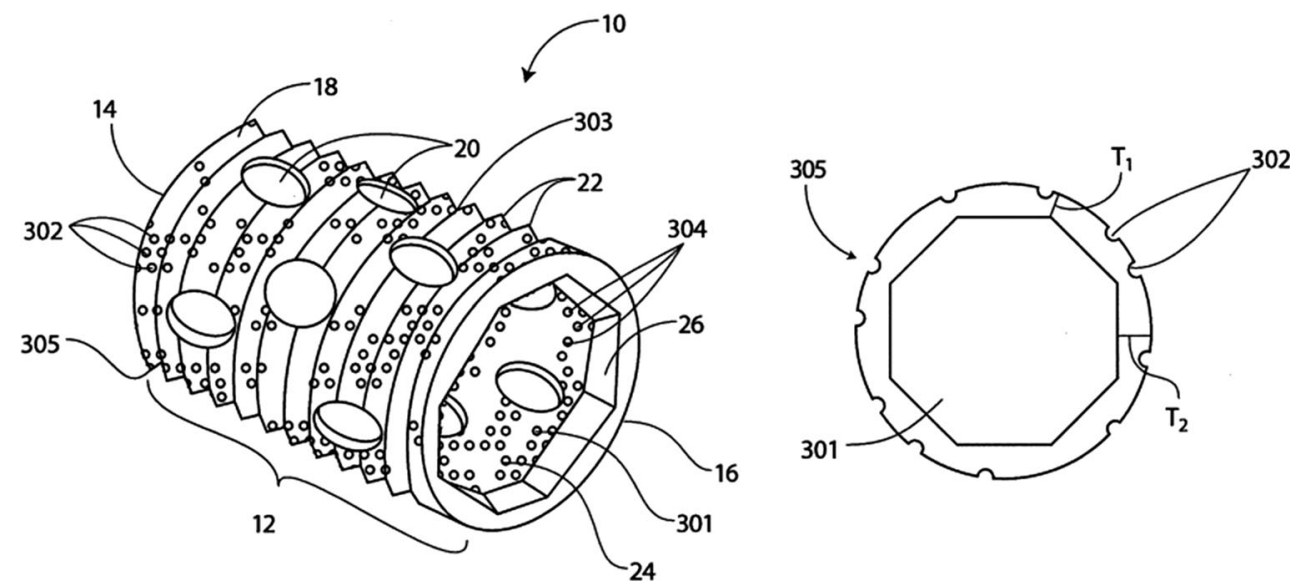

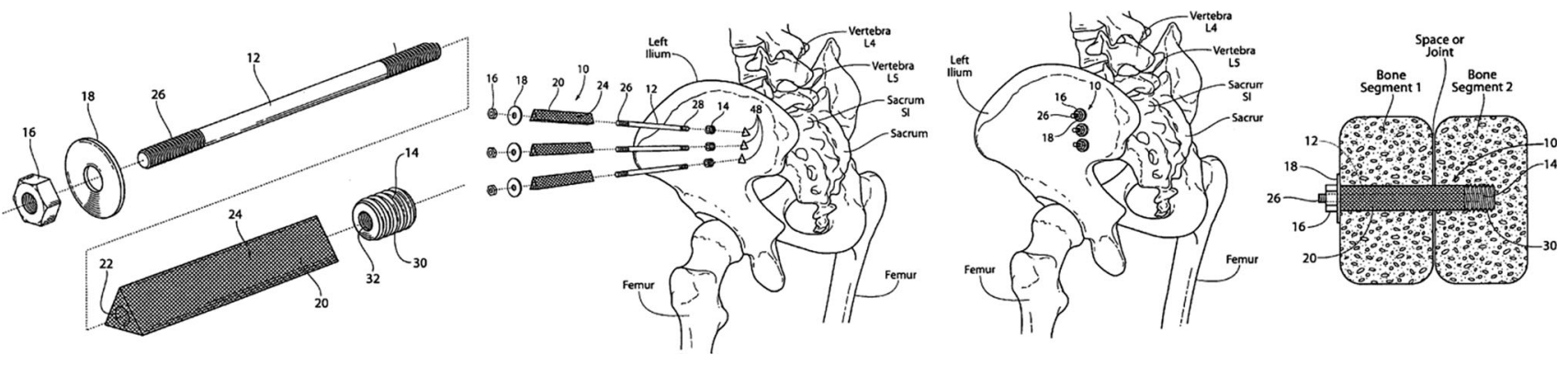

Fig. 17 An illustrative schematics compiled from the images provided in patent (Ref 96)
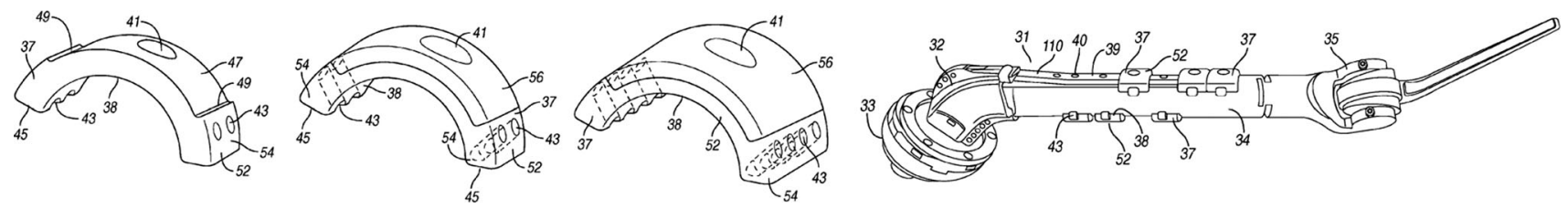

Fig. 18 An illustrative schematics compiled from the images provided in patent (Ref 99)

implants via atmospheric plasma spraying is patented in Ref 52. The core of the idea is spraying of rather big metallic powder particles $(180 \mu \mathrm{m})$ to form a thicker $(0.25$ $5 \mathrm{~mm})$, porous $(>35 \%)$ coating and subsequently removing the upper parts that may have been oxidized or formed nitrides, hydrides, carbides in the process. The removal process involved grit blasting with abrasive media that is soluble in a passivation solution. A part of the document is concerned with a potential use of inert gas shrouding to minimize the oxidation levels. The method should allow safe, effective and economical formation of the porous metal coating with high purity and desirable material properties such as high tensile strength, fatigue strength, strength-to-weight-ratio, flexibility, toughness, wear resistance and biocompatibility. The patent also covers arc wire and HVOF spray processes for achieving the same.

Also connected to biomedical use, a complex system for concurrent application of coatings onto multiple implant components is designed in Ref 53. The basis of the system is a holding fixture having multitude of mounting stations for installing of the implants such as femur balls or hip joint cups. Each of the mounting stations revolves individually, allowing the implants to be coated from all sides. Temperature of each of the implants is monitored independently. The system ensures economical and rapid application of the coating on the medical implant component with less residual stress, high quality, enhanced deposition efficiency and longevity, minimizing overheating of the coating layer.

A method for production of open-pore biocompatible surface layer filled with resorbable material is patented in Ref 54. The layer is deposited onto a surface of an implant with a thickness of $0.5-1.5 \mathrm{~mm}$, thereby allowing ingrowth of osteoblast cells. The viable methods for deposition include vacuum plasma spraying, physical vapor deposition (PVD), chemical vapor deposition (CVD), solgel process or sintering. At least $30 \%$ of the pores should be filled with the bioresorbable material of particle sizes from 

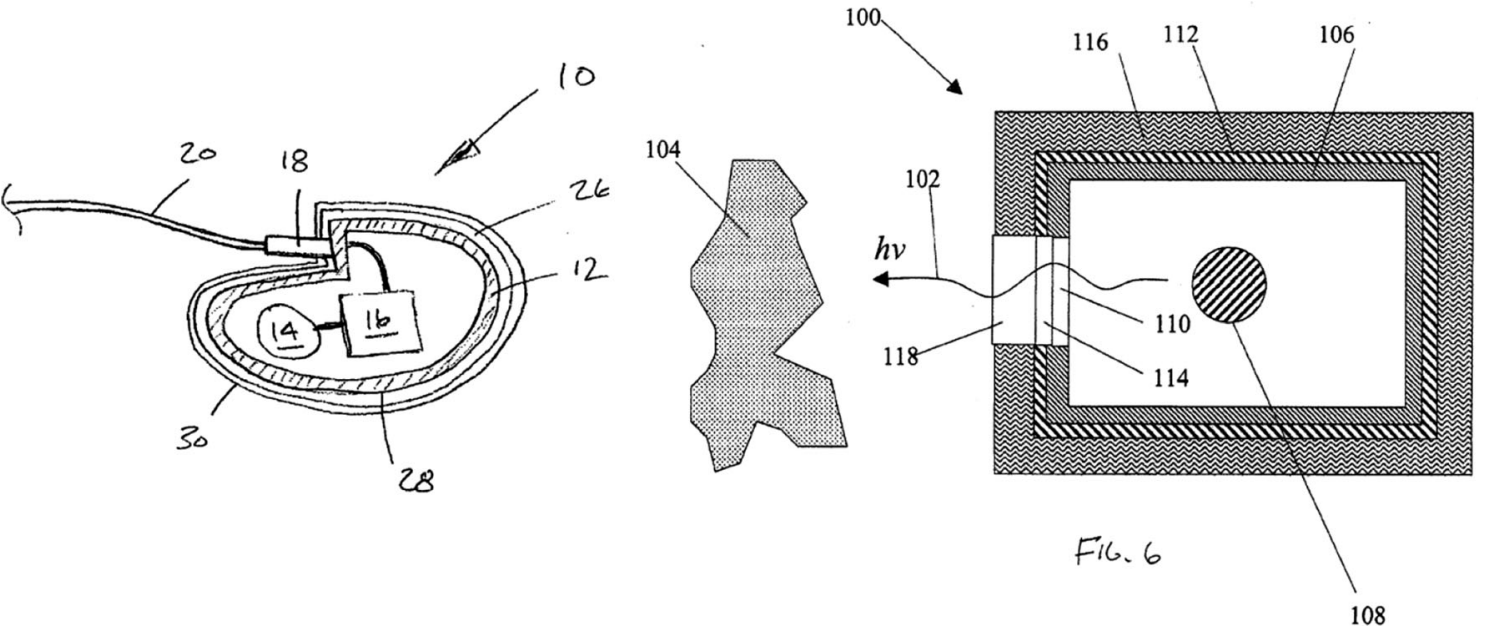

Fig. 19 An illustrative schematics compiled from the images provided in patent (Ref 51)

$0.005-50 \mu \mathrm{m}$. The document specifies these as calcium phosphates (HA, TCP), $\mathrm{SiO}_{2}, \mathrm{TiO}_{2}$, gelatin, collagen, hydrogels. The method could be applied to a variety of implants such as hip shaft, acetabular cups, femur components for knee joint replacement, or shinbone components for knee joint replacement, components for shoulder joints replacement, elbow joints replacement, toe joint replacement, finger joint replacement, for a component for fusion of vertebral body of lumbar spinal column and intervertebral disk replacement, and for transgingival implant systems, orthodontic implant systems, tooth implants and bone implants.

A method for increasing the lifetime of zirconium (Zircadyne 702 or 705 , Zircalloy) orthopedic implants is provided in patent (Ref 55). Using examples such as hip implant or knee implant, the surface of the metal stem comprises an oxidized 1-20- $\mu \mathrm{m}$ zirconium layer and an additional plasma-sprayed porous coating. The oxidation is made using air, steam, water or salt bath process conditions at temperatures of $540{ }^{\circ} \mathrm{C}$. The method is capable of effectively manufacturing non-toxic and biocompatible implants that resist articulative and fixation failures. Similar concept was filed by the same authors three years earlier (Ref 101), where a hip joint stem fitting into a femur using the oxidized zirconium concept was presented.

A method of fabricating medical implant with thermally sprayed surface layers comprising added carbides is given in Ref 102. Fabrication of the implant involves producing a sacrificial substrate (to be removed later) and plasma or HVOF spraying of cobalt-chrome particles, i.e., not highly brittle, biocompatible material with relatively good fatigue properties. Into the feedstock, at least $6.17 \%$ of carbide source material such as $10-200 \mathrm{~nm}$ graphite is added through an atomization process. Using the method, medical components that exhibit increased wear properties are produced.

Another combined process is used for fabricating medical implant components (Ref 56). These include femoral ball head, femoral knee, patella femoral bearing, modular tibial baseplate/tray and spinal implant, cardiovascular devices, stent and medical implant components for joints such as shoulder, ankle, elbow and finger. Technologically, the two-step process involves plasma or HVOF spraying of $100-500 \mu \mathrm{m}$ ceramic coatings onto the component and subjecting the coated portion to hot isostatic pressing or vacuum/controlled atmosphere sintering. The latter processes enable a chemical or diffusion bond among the substrate and the coating, yielding a bond strength of 48-62 MPa, reduced porosity of the coating, increased hardness and further provide a hardness gradient between the substrate and the coating. In addition, the metal ion release is reduced due to improvement in corrosion resistance. The coatings also exhibit improved scratch resistance and wear resistance. Almost identical patent was filed as (Ref 57).

Arc Spraying A rather general method of fabricating dense $>25 \mu \mathrm{m}$ ceramic coatings on medical implants through high-velocity thermal spray method is given in Ref 103. The (undisclosed, potentially high-velocity arc spraying) method is described as atmospheric and the inflight velocity of the particles should reach at least $200 \mathrm{~m} /$ $\mathrm{s}$, but remain below sonic speed. The deposited material is, according to the document, "any oxide, carbide, nitride or nitro-carbide of any of the following elements: $\mathrm{Si}, \mathrm{Ti}, \mathrm{Ta}$, $\mathrm{W}, \mathrm{Zr}, \mathrm{Nb}, \mathrm{Cr}, \mathrm{Al}$," i.e., the patent covers almost all known bioceramics. The target density of the coating is $>99 \%$ and, upon spraying, the grain size remains virtually unchanged (maximum $25 \%$ difference). Importantly, this is 
done without any post-treatment. The implants covered in this patent include femoral knee component, a tibial tray, a patella button, a femoral stem, and femoral head.

Cold Spraying A method of spraying of bioresorbable stents, markers, anchors, clips, sutures and orthopedic support devices is covered in patent (Ref 104). Specifically, the document deals with cold spray deposition of mixed coatings onto planar substrates, from which the stents are machined via EDM. The bioresorbable coatings are a mixture of "cathodic and anodic particles" bound together, creating a galvanic couple. The cathodic particles are either cobalt-chromium alloys, stainless steel, tantalum, or titanium, and the anodic particles are iron, iron alloys, or vanadium. All particles are preferably 1-10 $\mu \mathrm{m}$, and their specific weight and hardness should not differ by more than $50 \%$ (preferably 20\%). The material porosity is provided as $0.2 \%$ or less, a consequence of the cold spray deposition method. Surprisingly, the coating is "annealed after deposition to increase hardness" (probably by precipitation, undisclosed). Reportedly, it is possible to predetermine the bioresorption rate (i.e., the galvanic corrosion) in the coating production process.

Drug-delivery components prepared via thermal spraying method are provided in Ref 105. Under a controlled release rate, the therapeutic agents and drugs used in the components (antiplatelets, anticoagulants, antithrombins, anti-inflammatories and antiproliferatives) are useful to treat/reduce/prevent thrombosis or restenosis. Preparing of such medical device comprises forming a near-net shape porous component and its machining, followed by a coating deposition through cold spray, combustion spray process, arc wire spray, high-velocity oxygen fuel or detonation spray process (Fig. 20). The method is also useful for preparing stents, anastomosis clips, embolic protection filters, graft attachment systems, ring markers, guide wires, mitral valve repair devices, tubular or wire based implants, defibrillator or pacemaker lead tips and catheters or other delivery system devices. Another patent filed by the same authors (Ref 58) covers almost identical topic, focusing solely on cold spray technology this time.

A rather general idea was patented in 2006, a cold spray deposition of tissue-friendly materials onto (polyethylene) medical implant for joints, covered in Ref 106. Ideally, the (titanium) powder is supposed to reach $1-50 \mu \mathrm{m}$ and the final coating porosity in the $20-40 \%$ range.

In Ref 59, fabrication of a bond layer for attachment of ceramic or metallic coatings to thermoplastic substrates is presented, which could be used for implantable prosthetic bones. The bond layer contains $2-70 \%$ ceramic or metallic filler particles (HA, stainless steel, WC-Co, $\mathrm{ZrO}_{2}, \mathrm{Al}_{2} \mathrm{O}_{3}$, $\mathrm{SiO}_{2}, \mathrm{TiO}_{2}$ ) in a thermoplastic matrix that is compatible with the substrate. The bond layer deposited preferentially via cold spraying reduces chipping or wear of the ceramic or metallic coating and prevents damage to the thermoplastic (e.g., PET, PA, PBT, PS, PES, PPS, PA, PP, PEEK) substrate during the subsequent thermal spray deposition. The model top coating presented in the document is hydroxyapatite deposited via thermal spraying.

\section{Trends}

It is difficult to predict trends and future perspectives solely from the list of patented ideas. Upon compilation of this paper, it rather seems that there are several isolated areas that the individual submissions tend to wrap around (such as small differences in the designs of hip prosthesis).

Nevertheless, comparison with recent non-patent literature sources (such as the compilations of Heimann (Ref 107, 108) and Driver (Ref 109)) provides a clearer insight into what the future trends might be-although some of the areas are yet waiting for their first patent claims at the moment.

Aside from the coating materials, this paper covered also the substrate materials. In these, titanium and its alloys represent a long-term top-notch entry from the list. For decades now, the main alpha + beta alloy Ti6Al4V is slowly being replaced by alloys not containing cytotoxic vanadium. This said, the attention seems to shift to $\mathrm{Nb}$ containing alloys $\left(\mathrm{Ti}_{\mathrm{x}} \mathrm{Al}_{\mathrm{y}} \mathrm{Nb}\right)$ and also, lately, $\mathrm{Ti} 5 \mathrm{Al} 2.5 \mathrm{Fe}$ and TiZrNbTa. The patent claims contained in this paper suggest that attempts at further lowering the modulus of the substrates to match that of cortical human bone (10$30 \mathrm{GPa}$ ) are still ongoing. This could open up the application potential also to beta-type $\mathrm{Zr}$-containing titanium alloys (such as Ti13Nb13Zr) with moduli below $50 \mathrm{GPa}$ (Ref 107). Aside from titanium, certain well-proven alloys such as CoCrMo continue to be used. Recent journal papers on application of mechanical surface modifications (drilling, milling) of CrCrMo-based alloys (Ref 110) allow to anticipate patent claims in the near future. Tantalum exhibited several promising results so far and is already included in the latest patents (from 2012), too. Frequently covered in recent journal papers, magnesium and its alloys with their high specific strength, low stiffness and low density advantages have been used in bioapplications already (e.g., biodegradable osteosynthetic devices, cardiovascular stents). The application of $\mathrm{Mg}$ for orthopedic applications is currently hindered by its high corrosion rates in contact with extracellular fluids (associated with evolution of hydrogen gas that tends to counteract the osseointegration). Once this limitation is resolved, magnesium alloys could open up a whole new area of biomaterials applicable to endoprosthetic applications. 

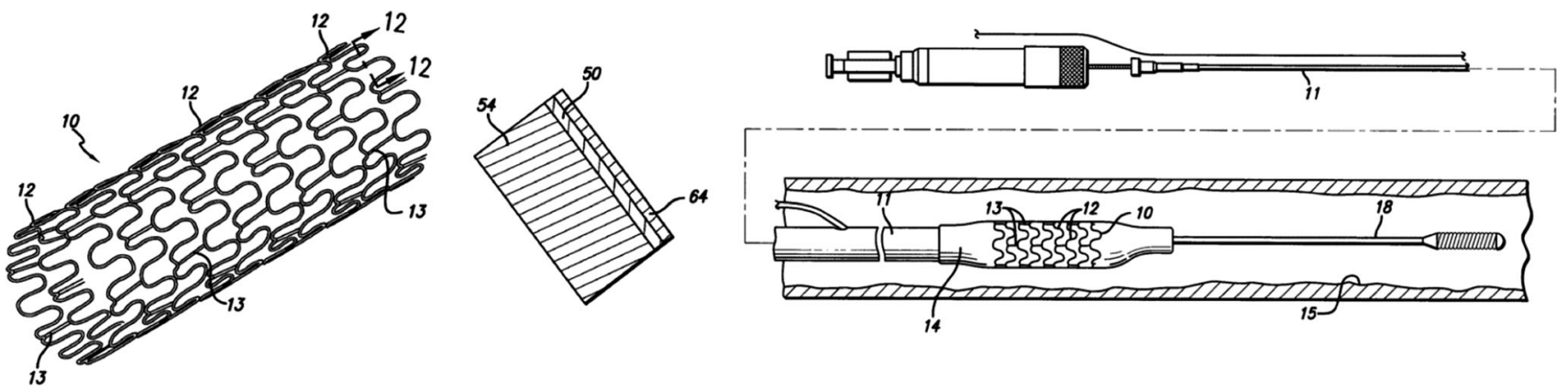

Fig. 20 An illustrative schematics compiled from the images provided in patent (Ref 105)

Concerning the materials used for coatings, the situation is very clear. Considering their natural resemblance to human bone tissues, calcium phosphates (dominantly HA, TCP) are the prime choice, as also reflected in the number of patents and research works filed in the last decades. A group of patents are devoted to improving the antibacterial properties of Ca-P coatings via addition of, e.g., silver (as also reported in the literature, (Ref 111). Very recently, a group of three materials with a promising potential appeared: gahnite $\left(\mathrm{ZnAl}_{2} \mathrm{O}_{4}\right.$ spinel, melting temperature indicated as $\left.1950{ }^{\circ} \mathrm{C}\right)$, baghdadite $\left(\mathrm{Ca}_{3}(\mathrm{Zr}, \mathrm{Ti})\left[\left(\mathrm{Si}_{2} \mathrm{O}_{7} / \mathrm{O}_{2}\right)\right]\right)$ and strontium hardystonite $\left(\mathrm{Sr}_{2} \mathrm{ZnSi}_{2} \mathrm{O}_{7}\right)$ showed a very promising potential for bioapplications. In fact, some studies suggested these may even be a sensible replacement for hydroxyapatite. Few patents on these materials reported in this paper may indicate the future trend for this group of materials.

A second group of materials considered for deposition via thermal spray method are oxide ceramics. For years, several non-resolved issues influenced the journal and patent literature (such as, e.g., the dispute on the three $\mathrm{TiO}_{2}$ polymorphs, anatase versus rutile versus brookite (Ref $7,112)$ ). These days, however, the Gordian knot seems to have been resolved: A clear trend to develop nanoscaled microstructure features could be observed. Despite their more complex fabrication as opposed to "traditional" microscaled coatings, the nanostructured oxide ceramics are more suitable for application and have already surpassed their predecessors in several areas. Importantly, the use of nanostructured powder feedstock allows the cold kinetic spray technology to enter the game, too, with its advantage of preserving the phase composition. A number of patents related to the deposition of nanostructured ceramics (oxides) could surely be expected in the forthcoming years.

Using other ceramics, the trend in using advanced bioceramic-polymer composites and bioglass for various applications is reflected in the patent literature. Frequently being associated with scaffolds, not many sources actually report these two material groups being treated via thermal deposition methods. Once the initial problems with, e.g., the thermal decomposition of these are overcome, it can be expected that a number of patents corresponding to bone augmentation (maxillofacial) will be filed, too. Another group of intensively developed materials are self-healing ceramics. However, no such patent sources could be located in our databases search (as of July 2018), and it is difficult to understand what is the major hindrance at the moment.

Among the metallic coatings reported in the patent literature, titanium and tantalum are of prime importance. With the development of non-oxidizing processes such as low-temperature HVOF and cold spraying, the application of metals for coatings is now wide open. In this paper, several such instances are summarized already. It could be expected that other metals such as alloyed (milled) or mixed feedstock will now be covered in patents on a regular basis.

Last group of materials yet waiting for its application via thermal spraying are polymers and engineering plastics. Supramolecular hydrogels, UHMWPE, PEEK and other polymer-based materials are currently being used in bioapplications. However, these are not processed through high-temperature thermal spray processes for obvious reasons. With the advent of cold spraying and first successful attempts to deposit these materials (UHMWPE, for instance, (Ref 113)), it could only be expected that the trend in this area will grow by an order of magnitude in terms of related journal and patent sources in the next decade.

Finally, a little prospect into the future: the era of thirdgeneration biomaterials is at its strongest at the moment. However, the pioneering research attempts to initiate and instigate $R \& D$ efforts for the fourth-generation biomaterials that are on the way already (e.g., Ref 114). The fourthgeneration biomaterials are based on integrating electronic systems with the human body to provide powerful diagnostic as well as therapeutic tools for basic research and clinical use. The functionalities of such biomaterial systems are thought to include manipulating cellular 
bioelectric responses for tissue regeneration as well as monitoring cellular responses with the aim to communicate with host tissues via bioelectric signals (Ref 107). This would surely open up a whole range of possibilities for the thermal spray method. This is probably the field where the majority of patents are going to be filed in the new decade.

\section{Glossary}

The following text contains numerous terms associated primarily with the biological sector. Secondly, a whole set of abbreviations used for the biomaterials appears throughout the paper. The following list is provided to familiarize the thermal spray researchers with the less commonly encountered terms. To complete the list of all abbreviations used throughout this paper, abbreviations pertaining to the thermal spray methods are provided in the table, too.

\begin{tabular}{|c|c|}
\hline Acetabulum & $\begin{array}{l}\text { Concave cavity in pelvis, femur bone contact } \\
\text { region }\end{array}$ \\
\hline Anastomosis & Connection between veins or nerves \\
\hline Angiogenesis & $\begin{array}{l}\text { Process of formation of new blood vessels, } \\
\text { encountered in healing }\end{array}$ \\
\hline Anticoagulants & $\begin{array}{l}\text { Chemical substances that prevent blood } \\
\text { coagulation, often employed to prevent } \\
\text { thrombosis }\end{array}$ \\
\hline $\begin{array}{l}\text { Anti- } \\
\text { inflammatories }\end{array}$ & Substances used for treatment of inflammation \\
\hline Antimicrobial & $\begin{array}{l}\text { Substances used for killing microorganisms or } \\
\text { preventing their growth }\end{array}$ \\
\hline Antiplatelets & $\begin{array}{l}\text { Substances used for preventing blood platelets } \\
\text { coagulation, preventing, e.g., thrombosis }\end{array}$ \\
\hline Antiproliferatives & $\begin{array}{l}\text { Substances inhibiting cell multiplication and } \\
\text { growth }\end{array}$ \\
\hline Antithrombins & $\begin{array}{l}\text { Proteins produced in liver that inactivate } \\
\text { coagulation enzymes }\end{array}$ \\
\hline $\begin{array}{l}\text { Articulation, } \\
\text { articulative }\end{array}$ & $\begin{array}{l}\text { Joint, connection of two bones such as knee or } \\
\text { hip }\end{array}$ \\
\hline Autologous & Derived from the same individual \\
\hline $\begin{array}{l}\text { Bacillus } \\
\text { pyocyaneus }\end{array}$ & $\begin{array}{l}\text { Equally Pseudomonas aeruginosa, bacterium } \\
\text { partially resistant to antibiotics }\end{array}$ \\
\hline Bactericidal & Substance killing bacteria, often antibiotics \\
\hline Biocidal & Substance killing of any harmful organisms \\
\hline BMP & $\begin{array}{l}\text { Bone morphogenetic proteins, inducing } \\
\text { formation of bones and cartilage }\end{array}$ \\
\hline Catheters & $\begin{array}{l}\text { Medical devices inserted into body to treat } \\
\text { diseases, often hollow tubes }\end{array}$ \\
\hline Cervical & Pertaining to neck, part of spine \\
\hline Coccygeal & Pertaining to tailbone, part of spine \\
\hline Cochlear & Pertaining to inner ear \\
\hline Collagenous & Producing or containing collagen \\
\hline Cranial & Pertaining to skull \\
\hline Craniofacial & Pertaining to facial structures of a head \\
\hline
\end{tabular}

CS

Cytotoxicity

Distal

\section{EDM}

Embolism, embolic

ePTFE

Escherichia Coli

Exosomatic

FGM

Gelatin

Gingival

HA

HVOF

Iatrogenic

Intraosseous

Intravenous

Lumbar

Mammoplasty

Mandible bone, mandibular

Masticatory power

Maxillofacial

Mitral valve

Orthodontic

Osseoconductivity

Osseointegration

Osteoacusis

Osteoblast

Osteocalcin

Osteoconductivity

Osteogenesis

Osteosynthetic

Osteotomy

PA

PBT

PDO

PEEK

PES

PET

PGA

PLA
Cold spraying

Toxicity toward cells

Farther from the point of attachment, often distal end of bone

Electrical discharge machining

Pertaining to blockage of blood vessel

Expanded polytetrafluoroethylene, for instance GoreTex

Bacterium commonly found in lower intestine

From outside of the body

Functionally graded materials

Colorless ingredient, often used as a binder

Pertaining to gums

Hydroxyapatite (hydroxylapatite)

High-velocity oxy-fuel spraying

Induced inadvertently by a surgeon or medical treatment

Situated, performed, or occurring within or entering by way of bone

Situated, performed, or occurring within or entering by way of vein

Pertaining to abdominal part, part of spine Surgical procedure pertaining to breasts Jawbone, the strongest of bones in face

Related to chewing

Pertaining to jaws and face

Valve in the heart between left atrium and left ventricle

Dentistry focusing on prevention and correction of malpositioned teeth and jaws

Property of material that promotes process of bone growth

Process of bone adherence to the implant

Conducting of sound via bones, the ability of bone to conduct sound

Single nucleus cells that synthetize bone

Bone-building protein produced by osteoblast cells

See osseoconductivity

Formation of new bone tissue

Pertaining to fixation of bone fracture using implants

Surgical procedure pertaining to cutting of bones

Polyamide

Polybutylene terephthalate

Polydioxanone, crystalline polymer

Polyether ether ketone

Polyether sulfone

Polyethylene terephthalate

Polyglycolide, polyglycolic acid, thermoplastic polymer 
Polylactide, polylactic acid, thermoplastic polymer

\section{PLLA}

\section{L-chiral form of PLA}

Povidone iodine

Antiseptic used for skin disinfection

$\mathrm{PP}$

PPS

Proximal

PS

Pseudomonas

aeruginosa

PTMC

PUR

Restenosis

Sacral

Sacroiliac joint

Sacroiliitis

SBF

Scoliosis

Spinal stenosis

SPS

Staphylococcus aureus

Subcutaneous

Synostosis

TCP

Thoracic

Thrombosis

Tibia

Transcutaneous

Transgingival

TS

UHMWPE

Vascularization

Veneers

Vertebrae, vertebral
Polypropylene

Polyphenylene sulfide

Closer to the point of attachment, often proximal end of bone

Polystyrene, alternatively plasma spraying

See Bacillus pyocyaneus

Polytrimethylene carbonate

Polyurethane

Recurrence of stenosis, a narrowing of a blood vessel

Pertaining to sacrum bone, part of spine

Joint between the sacrum and the ilium bones of pelvis

Inflammation of sacroiliac joint

Simulated body fluid, a solution simulating human blood plasma

Sideways distortion of a spine

Narrowing of the spinal canal causing pressure on spinal cord and nerves

Suspension plasma spraying

Biochemically active bacterium found in human body, causes infections and intoxications

Pertaining to hypodermis, lowermost layer of skin tissue

Fusion of two bones

Tricalcium phosphate, $\mathrm{Ca}_{3}(\mathrm{PO} 4)_{2}$

Pertaining to chest, part of spine

Obstruction of blood flow through formation of blood clot

Shinbone, the larger of the two leg bones below knee

Penetrating the skin

Penetrating the gums

Thermal spraying

Ultra-high molecular weight polyethylene, thermoplastics

Formation of blood vessels and capillaries in living tissue

Layer of material placed over a tooth for protection and aesthetics

Bony or cartilaginous segments composing the spinal column
Acknowledgment Compilation of the paper was supported through Czech Science Foundation grant GB14-36566G "Multidisciplinary research centre for advanced materials."

\section{References}

1. K.A. Gross and E. Ezerietis, Juniper Wood as a Possible Implant Material, J. Biomed. Mater. Res., 2003, 64A, p 672-683

2. M.E. Pons, Developing Hydroxyapatite CAPS Coatings on Metallic Implants for Tissue Replacement, Ph.D. Thesis, Nanyang Technological University, Singapore 2004

3. R.E. Ant and I. Wang, Physical and Chemical Aspects of Biomaterials Used in Humans, in Implantation Biology: The Host Response and Biomedical Devices. CRC Press, Boca Raton, 1994, p. $13-38$

4. R.C. Eberhart, H. Huo, and K. Nelson, Cardiovascular Materials, MRS Bull., 1991, 16, p 50-54

5. P. Chagnon and P. Fauchais, Thermal Spraying of Ceramics, Ceram. Int., 1984, 10(4), p 119-131

6. S. Sampath, X.Y. Jiang, J. Matejicek, L. Prchlik, A. Kulkarni, and A. Vaidya, Role of Thermal Spray Processing Method on the Microstructure, Residual Stress and Properties of Coatings: An Integrated Study for Ni-5 wt.\%Al Bond Coats, Mater. Sci. Eng. Struct. Mater. Prop. Microstruct. Process., 2004, 364(1-2), p 216-231

7. J. Cizek, K.A. Khor, and I. Dlouhy, In-Flight Temperature and Velocity of Powder Particles of Plasma-Sprayed $\mathrm{TiO}_{2}$, J. Therm. Spray Technol., 2013, 22(8), p 1320-1327

8. V. Palka, E. Postrkova, and H.K. Koerten, Some Characteristics of Hydroxylapatite Powder Particles after Plasma Spraying, Biomaterials, 1998, 19(19), p 1763-1772

9. Clarivate Analytics, Web of Knowledge-Derwent Innovation Index. http://www.webofknowledge.com

10. European Patent Office, Espacenet. https://worldwide.espacenet. com

11. United States Patent and Trademark Office, Patent Full-Text Databases. http://patft.uspto.gov/netahtml/PTO/index.html

12. Q. Bao and T. Brown, Implantable device i.e. Weight-Bearing Implant, for Being Implanted into Weight-Bearing Joint, has Camming Surface Connected to Implant Body, Where Mechanical Bond Strength Between Implant Body and Coating About Specific MEGA PASCAL, US2009276053-A1, 2009

13. T.C. Prentice and A.R. McCabe, Applying a Coating to a Substrate Material, Comprises Plasma Spraying Powder of Titanium Dioxide onto a Substrate Material to Form an Initial Coating, and Applying A Further Coating of Metal and/or Hydroxyapatite onto the Initial Coating, WO2012110816-A1, 2012

14. R. Ahmed and G.H. Markx, Coating an Article, e.g. Implant for Surgical or Dental Use Involves Spray Coating the Powder Comprising Coated Particles onto Surface of Article to Form Composite Coating, US9421151-B2, 2016

15. O.A. Dudareva, I.P. Grishina, V.N. Lyasnikov, and A.V. Lyasnikova, Method for Making Implants Involves Multilayer Plasma Spraying of Biologically Active Coating onto Metallic Substrate of Implants, RU2529262-C1, 2014

16. L. Jiang, S. Lin, and L. Wang, Titanium-Hydroxylapatite Gradient Coating for Titanium Alloy Implant Surface, has Titanium Powder Layer, Two Titanium Powder and Hydroxylapatite Mixed Layers and Hydroxylapatite Layer that are Arranged from Inside to Outside, CN101612418-A, 2009

17. L. Gan, S.C. Jani, M.L Scott, Marcus, and S.C. Giani, Coating for Medical Implant, Comprises Osseointegration Agent and Antimicrobial Metal Agent Comprising Silver, Copper and/or Zinc, US9839720-B2, 2017

18. Y. Chen, X. Zheng, H. Ji, C. Ding, and Y. Xiang, Antimicrobial Type Hydroxyapatite Composite Coating Includes Metal Silver Powder as Antimicrobial Additive Ingredient and Hydroxyapatite Powder, CN100549109-C, 2009 
19. J. Zhou, Iodine Antibacterial Hydroxyapatite Composite Coating Used for Coating Titanium and Titanium Alloy Based Substrate Used as Prosthetic Implant, Comprises Hydroxyapatite and Povidone Iodine Particles, CN102417741-A, 2012

20. L. Song, Y. Huang, L. Gan, Y. Wu, X. Liu, F. Wu, Y. Xiao, and Z. Tian, BIOMEDICAL MATERIAL i.e. Hydroxyapatite Coating Containing Silver ion Biomaterial, Contains Hydroxyapatite Coating that Contains Silver ion Which is Sprayed on Substrate Material by Plasma, CN101797399-A, 2010

21. H. Gruner, P. Gruner, and F. Tourenne, Implant i.e. CementLess Implanted Prosthesis, for e.g. Traumatology, has Cover Layer Formed of Powder by Application of Thermal Spray Method, Where Powder has Calcium Phosphate e.g. Hydroxylapatite, and Antibacterial Active Ingredients, EP2224970-B1, 2018

22. J. Fencl, J. Fojt, and L. Joska, Revision joint Implant Device for Performing Total Replacement of Femoral and Acetabular Components, has Transition Portion Whose Outer Surface is Provided with Protective Porous Surface Layer that is Matched with Integral Surface Layer, CZ306816-B6, 2017

23. J. Chen, J. Feng, Y. Huang, X. Liu, L. Song, F. Wu, Y. Xiao, and J. Cheng, Preparation of Multiple Pore Hydroxyapatite Coating on Biomedical Material, e.g. Titanium, by Spraying Plasma of Hydroxyapatite Suspending Liquid, Adding Pore-Creating Agent, e.g. Ethanol, Injecting to Plasma Flame Kernel, and Sedimenting, US8877283-B2, 2014

24. F. Wu, L. Song, Y. Xiao, X. Liu, Y. Huang, Y. Wu, and J. Chen, Suspension Injection Type Plasma Spray Coating Device For Preparing Biologically Active Hydroxyapatite Coating, Comprises Plasma Spray Gun, Metal Substrate, Substrate Fixed Beam, Storage Container, Suspension Conveying and Injection Systems, CN101250682-B, 2011

25. J. Chen, Y. Huang, X. Liu, L. Song, F. Wu, Y. Wu, and Y. Xiao, Suspending Liquid Injection Plasma Spraying Device Useful for Preparing Biological Active Coating Of Hydroxyapatite, Comprises a Plasma Spray Gun, a Metal Substrate, a Substrate Fixing Rack, and a Suspending Liquid Conveying System, CN201195743-Y, 2008

26. F. Wu, Y. Huang, X. Liu, Y. Wu, Y. Xiao, L. Song, and J. Chen, Preparation of Hydroxyapatite Biological Activity Coat by Spray Coating Suspension Plasma for Medical Consumption Comprises Preparing Hydroxyapatite Suspension, Transferring, Pouring and Generating Hydroxyapatite Biological Activity Coat, CN101250681-B, 2010

27. R.E. Riman and C. Sever, Preparation of Nanoscale Hydroxyapatite Particles Useful e.g. as Granular Fill Compounds, Bone Implant Materials Involves Combining Calcium Ion Source Having Calcium Acetate and Phosphate Ion Source Under Ambient Conditions, US8287914-B2, 2012

28. T. Huang, J. He, L. Gan, Y. Wu, F. Wu, and Z. Tian, Biomedical Material for Bone Formation, has Substrate Material Whose Surface is Compounded with Porous Calcium Phosphate Coating that is Compounded with Collagen so as to Build Porous Calcium Phosphate-Collagen Composite Coating, CN102145194-A, 2011

29. J. Fencl and J. Simek, Surface Treatment of Implants, that is Bone Preferably Joint Implants, Comprises Thermal Application of a Mixture of a Powdered Material Containing Hydroxyapatite Powder, and Titanium Powder on Surface, CZ201500934-A3; CZ306822-B6, 2017

30. S. Ban, L. Cui, D. He, J. Jiang, X. Li, Z. Wang, L. Zhao, Q. Zhao, and Z. Zhou, Preparation method for Making Hydroxyl Apatite Coating Through Cold Spraying, Involves Spraying Dried Hydroxyl Apatite Powders onto Matrix of Biomedical Implanted Metal Material Using Cold Spraying Device, CN101591777-B, 2011
31. S. Ban, L. Cui, D. He, J. Jiang, X. Li, Z. Wang, L. Zhao, Q. Zhao, and Z. Zhou, Preparation Method of Hydroxyl Apatite Coating by Micro-beam Plasma Spraying for Medical Implant Pieces of Tooth Root and Artificial Joint Involves Providing Powder Conveying Gas with Predetermined Flow Rate and Conveying Rate, CN101591759-B, 2011

32. B. Hou, Y. Huang, T. Li, Z. Liu, Z. Qiao, Z. Xiong, G. An, and G. Qin, Crystallization of Plasma-Sprayed Hydroxyapatite Coating Used for Surgical Implant, Involves Providing Hydroxyapatite Coating Product into Closed Container, Introducing Vacuum and Saturated Steam, Heating Container, and Cooling, CN104164644-A, 2014

33. B. Yang, Y. Huang, J. Feng, J. Chen, and X. Zhang, Method for Post Treatment of Plasma Spraying Hydroxyapatite Coating, CN100357485-C, 2007

34. Y. Lu, J. Wang, and M. Li, Surface Nanocrystallization Method For Hydroxyapatite Coating, CN100348276-C, 2007

35. H. Grundei, Subcutaneous Intramuscular Camp for Rigid Transcutaneous Implant in Bone Stump, Comprises Distance Piece Having Rigid Socket Surface with Intracorporal Coupling Element and is Placed Between Implant and Extracorporal Coupling Device, EP1827317-B1, 2006

36. H. Zimmermann, Thermal Sprayed Surface Layer Made of Titanium on a non-metallic Substrate of an Orthopedic Implant, Comprises an $\mathrm{x}$-Ray-Sensitive Mixture Made of Biocompatible Indicator Metal in Relation to Titanium, EP2199423-B1, 2013

37. R. Lerf, H. Schmotzer, and S. Siegmann, Open-Pore Biocompatible Surface Layer for Application to an Implant Comprises a Coherent Pore Network and has a Defined Surface Area, EP1942961-B1, 2013

38. Y. Xie and J. Zeng, Manufacture of Patterned Titanium-Coated Hard Tissue Replacement Material Involves Sand-Blasting Metal Implant, Cleaning, Spraying Titanium Powder on Metal Implant by Arc Plasma Method, and Forming Titanium Surface Layer, CN103805987-B, 2016

39. S. Cheng and X. Lu, Human Body Bone Substitute Connecting Piece for Use as Biological Medical Material, has Human Body Bone Substitute Connecting Piece Base Provided with Porous Titanium Surface Layer that is Coated with Titanite Layer, CN202982311-U, 2012

40. V.M. Frauchiger, S. Jaggi, and T. Wippich, Plasma Spray Process for Modifying Substrate Used in e.g. Hip Implants Involves Introducing two Materials into Plasma Source to Produce a Plasma Spray, Where Second Material at Least Partially Melts in the Plasma and Binds to First Material, WO2010037562-A2, 2010

41. M. Mitrovic, Method for Producing Structured Coating on Part of Surface of Artificial Femoral Knee Joint Implant to be Placed in Femur for Joint Replacement, Involves Hardening thin Layer, and Abrasively Processing and Functionalizing Produced Layer, WO2012126448-A1, 2012

42. J. Schleicher, J.K. Barrett, and J. Ault, Coating Cobalt-Chromium Alloy Medical Implant, by Applying Coating of Pure Titanium to Surface of Medical Implant by Cold Spray Process, and Diffusion Bonding Coating and $\mathrm{CoCr}$ Alloy Medical Implant Using Hot Isostatic Pressing, WO2014137316-A1; CA2903188-A1; $\quad$ EP2964802-A1; US2016030632-A1; EP2964802-A4, 2014

43. M. Kumar, Making Implant for Replacing Joint of Patients Involves Coating Textured Dies Surface with Powdered Metal, Injecting Slurry into Die Cavity, Casting Slurry Material, Removing Ceramic Shell, Plasma Spraying Layer onto Surface of Stable Dome, US2010136214-A1, 2010

44. M. Kumar, Formation of Acetabular Cup by Providing Working Surface, Spraying First Layer of Material Having First Composition onto Working Surface Defining Acetabular Shell, and 
Removing Acetabular Shell from Working Surface, US7655162-B2, 2010

45. X. Liu, X. Zhao, and C. Ding, Preparing Nano-Titanium Oxide Coating Layer Having Bioactivity, CN100346001-C, 2007

46. R.S. Lima, B.R. Marple, H. Li, and K.A. Khor, Making of Biocompatible Coating for an Implant, e.g. Component of Artificial Hip Joint, Involves Thermally Spraying the Particles onto Substrate to Form Coating, and Controlling the Spray Parameters, US2006199024-A1, 2006

47. H. Zheng and X. Zaho, Preparing Titanium-Niobium Oxide Composite Coating for Surface Activation Treatment Comprises Preparing Coating Powders, Material Cleaning and Sand Blasting, Plasma Spraying, and Soaking in Energy Body Fluid, CN102816988-B, 2014

48. L. Huang, H. Ji, Y. Liang, Y. Xie, and X. Zheng, Bone Replacing Material of Baghdadite Coating-Titanium Alloy, Useful for Inducing Formation of Bone-Like Apatite in Simulated Body Fluid, Comprises Titanium and Its Alloy as Matrix and Coating is Deposited on Matrix by Plasma Spray Coating, CN102049065-A, 2011

49. J. Chang, C. Ding, Y. Xie, W. Zhai, and X. Zheng, Hard Tissue Substitute Comprises Magnesium Silicate Coating Layer Which is Coated on Substrate such as Titanium or Titanium Alloy, CN101658693-B, 2008

50. D.E. Lawrynowicz, H. Zeng, and Z. Zhang, Producing Refined Chromium Oxide Powder, Useful in Thermal Spraying a Coating on an Implant (which is medical implant), Comprises Acid and Reduction Washing of Chromium Oxide Powder, and PACKAGING the Chromium Oxide Powder, US2009162273A1, 2009

51. W.J. Dalzell and K.H. Heffner, Integration of Radiation Shield, e.g. Tungsten, with Implantable Medical Device with Biocompatible Coating, e.g. Pacemaker, Involves Thermally Spraying Radio-Opaque Composition Particularly Around Electronic Circuitry of Medical Device, US2007055147-A1, 2007

52. E. Garofalo, M. Meehan, R. Montalbano, J. Wang, J. Whalen, and E. Garafalo, Forming Porous Metal Coating Over Substrate, by Thermally Spraying Metal Coating Material Over Surface of Substrate to form Applied coating Including Impurity-Rich Portion, and Removing The Portion of Applied Coating to Form the Coating, US9023419-B2, 2015

53. D.E. Lawrynowicz, A. Wang, Z. Zhang, and J. Krajewski, System for Applying Coating of Desired Material onto Medical Implant Component, Comprises Thermal Sprayers, Rotatable Holding Fixture Having Mounting Stations, Feeders for Supplying the Desired Material to the Sprayers, and Control Device, US7981479-B2, 2011

54. S. Koenig and H. Schmotzer, Open-pore Biocompatible Surface Layer for Use as Implant for Hip Shaft, Bowls for Hip Joints, Femur Components for Knee Joint Replacement, Shinbone Components for Knee Joint Replacement, is Disposed on Raw Surface of Implant, WO2009097968-A3, 2009

55. R.E. Brosnahan, R. Fesmire, H. Gupta, D.A. Heuer, G. Hunter, and V. Pawar, Manufacturing Medical Implant e.g. Hip Implant Having Oxidized Zirconium Surface and Porous Coating, by Forming Implant, Oxidizing Implant to Form Surface of Oxidized Zirconium, and Applying Coating to Portion of Implant by Plasma Spray, US2009012611-A1, 2009

56. D.E. Lawrynowicz and A. Wang, Fabricating Medical Implant Component such as Femoral Ball Head Component, Useful in e.g. Hip Replacement Surgery Involves Spraying Particles on Bearing Portion of Substrate; and Subjecting Coated Bearing Portion to Vacuum Sintering Process, EP1806155-B1, 2010

57. A. Wang, D.E. Lawrynowicz, Z. Zhang, and D. Lawrynowicz, Medical Implant Component e.g. Femoral Ball Head Component, Fabrication for e.g. Hip Replacement Surgery, Involves
Spraying Particles of Ceramic Material onto Bearing Portion of Substrate by Thermal Type Spraying Process, EP1808186-B1, 2010

58. P.A. Kramer, Manufacturing Medical Device e.g. Drug Eluting Stent, Guide Wires, Lead Tips, Catheters, Markers Involves Forming Porous Substrate from Biocompatible Material Using Spray Process and Processing Porous Substrate INTO Medical Device, US7514122-B2, 2009

59. M.N. Bureau, J. Legoux, S. Belanger, and J.G. Legoux, Tie layer for Bonding Ceramic or Metallic Coating to Thermoplastic Substrate such as Implantable Prosthetic Bone, Contains Filler Particles such as Ceramic and/or Metallic Particles in Thermoplastic Matrix that is Compatible with Substrate, CA2593781-C, 2011

60. C.P. Cornelius, R. Schoutens, R. Gheorghe, and A. Mootien, Mandibular Bone Plate for Use With Mandible, has Extension Portion for Defining Bone Facing Surface, Where Extension Portion is Oriented such that line Tangential to Inferior End and Superior End of Bone Facing Surface is Rotated, WO2014158740-A1, 2014

61. V.N. Lyasnikov, O.D. Muktarov, and V.V. Perinskii, Method for Making Intraosseous Carbon-Nanocoated Dental Implant Involves Sand-Blast Finish of an Implant Surface by Aluminium Oxide Particles, RU2490032-C1, 2013

62. N. Urakabe and S. Urakabe, Dental Implant Useful in Surgery Process, has Cylindrical Core Material and Recrystallized Apatite-Based Ceramic Coating Layer Having Two or More Calcium-Phosphate-Type Compounds Which Differs in Melting Points, JP5891150-B2, 2016

63. F. Nakada, Component for Installing Artificial Hip Joints in Recess Cover of Pelvis, has Liner Whose Outer Surface is Provided with Opposing Surface Facing Another Surface, Where Opposing Surfaces are Made to Contact with Sides of Recessed Part, JP2013063103-A, 2013

64. B.W. Schneider, R. Simon, D. Lindsey, and S.A. Yerby, Modular Implant for Fixation/Fusion of Sacroiliac Joint, has Transverse Support Struts Arranged in Rectilinear Configuration at Proximal and Distal Ends of Repeating Internal Portion which is Positioned Between Distal and Proximal Portions, US2017296244-A1, 2017

65. B.W. Schneider, R. Simon, D. Lindsey, and S.A. Yerby, Modular Straight Implant for Performing Fixation or Fusion of Sacroiliac Joint of Patient for e.g. Degenerative Sacroiliitis, has First Guide Pin Receptacle Located Along Longitudinal Axis of Solid Elongate Body, US9662157-B2, 2017

66. B. Walter, D. Brazil, and T. McTighe, Femoral Prosthesis e.g. Hip Prosthesis, for Installing or Fixing at Proximal End of Proximal Femur of Human Patient in Total Hip Replacement Procedure, has Thinner Connecting Body Placed Between Columns, Where Columns are Spaced Apart, US8470049-B2, 2013

67. N. Hansell, E. Dwyer, and J. Bennett, Artificial Disc, Useful for Replacing Damaged Intervertebral Disc, Comprises Superior Core with Superior Surface Provided to Contact Inferior Surface of Superior Endplate, Inferior core to Connect to Superior Core, and Inferior Endplate, US9017410-B2, 2015

68. A. Balasubramanian, J. Bennett, N. Hansell, and J.B. Bennett, Artificial Disk for e.g. Replacing Intervertebral Disks, of Patient Injured or Damaged as Degenerative Disk Disorder Result, has Support Assembly Placed on Outer Surfaces of Endplates and for Coupling Superior Endplate to Inferior Endplate, US9937051-B2, 2018

69. S.D. Cook and S.L. Salkeld, Implant Device for Treating Lumbar Spinal Stenosis of Patient, has Vertebral Attachments Comprising Connecting Components that Affix Magnets to Superior or Inferior Vertebrae, Where Connecting Components Comprise Extension, US2014025122-A1, 2014 
70. S. Petersheim and R. Agard, Bone Plate i.e. Spinal Plate, for Joining Adjacent Vertebrae to Treat Spinal Deformities, has Ridge Connected to Bottom Part and Inserted into Bone, and Hole Receiving Bone Screw for Attaching Plate to Bone, EP2753256-A1, 2014

71. P. Raugel and E. Jones, Flexible Acetabular Cup makes External Choral Dimensions of Cup, Which Runs Across Separation or Opening Between Arms, Greater than External Diameter of Partly Spherical Portion, EP1884220-B1, 2011

72. Y. Hai, Q. Luan, and Z. Zhou, Cost-Effective Artificial Bone with High Strength, Excellent Hardness, Toughness, and Corrosion Resistance, Comprises Middle Layer Comprising high Strength Carbon Fiber, CN202355616-U, 2012

73. T.C. Prentice, R.L. David, M.E.L. Pickford, and A.D. Turner, Implant Useful in Surgical Procedure e.g. Hip Replacement, Contains Metal Structure Coated with Biocompatible Metal by Plasma Spraying, and Biocidal Metal Cations Incorporated in Coating, EP2101835-B1, 2010

74. T.C Prentice, M.E.L. Pickford, D.R Lewis, and A.D. Turner, Implant for Contacting with a Bone During e.g. Prosthetic Surgery, Comprises Metal Structure Having a Surface with a Ceramic Coating Containing Hydroxyapatite and Silver Ions that Gradually Leach out in Body Fluids After Implantation, EP2316499-B1, 2013

75. H. Ao, Y. Liu, Y. Chen, H. Chen, C. Wang, W. Yuan, X. Wu, X. Wang, and X. Zheng, Plasma Spray Coating Orthopedics Screw, has Screw Main Body Whose Surface is Coated with Plasma Spray Coating, Where Screw Main Body is Made of Titanium Alloy, CN202288439-U, 2012

76. B.D. Hahn and D.S. Park, Preparation of Nano-structured Hydroxyapatite Coating Layer, Comprises Putting Hydroxyapatite Powder in Powder Chamber, Placing Metal Substrate in Deposition Chamber, and Keeping Deposition Chamber in Vacuum State Using Vacuum Pump, US2011281127-A1, 2011

77. C.G. Sidebotham, Load Bearing Implant, Useful for Medical Applications Including e.g. Femoral Head Replacement for Hip, Comprises Femoral Implant Stem Having Male Locking Tapered Fitting for Attachment to Internal Female Taper of Head, and Neck-Collar Area, US8778030-B2, 2014

78. A. Podolsky and Y. Garbuzov, Dual-Taper Lock Modular Prosthetic Hip System for Performing Minimally Invasive Totalor Hemi Hip Arthroplasty in Hip of Patient, has Prosthetic Femoral Head Implant Rotatably Fitted Within Acetabulum, US8579985-B2, 2013

79. S. Abdou, Orthopedic Device Assembly for Concurrently Placing Implantable Spacers into Intervertebral Disc Space Between Superior and Inferior Vertebral Bones, has non-Implantable Placement Instrument with Cavity Containing Bone Forming Material, US8845728-B1, 2014

80. P. Brun, S. Chegini, and P. Lindenmann, Intervertebral Implant i.e. Orthopedic Implant, for Implant Assembly to Implant in Intervertebral Disk Space in e.g. Spine Region, has Fixation Assembly Rotated Within Implant Body About Transverse Axis from Retracted to Extended Position, US8545563-B2, 2013

81. D.C. Blackburn, V. Carvajal, R.H. Dixon, C.F. Gardinier, D.P. Harding, T. Medford, B.J. Pope, J.K. Taylor, Component for Prosthetic joint e.g. Artificial Hip Joint, Comprises Sintered Carbide Substrate Comprising Titanium Carbide and Titanium Sintering Metal, Sintered Diamond Articulation Surface Formed on Substrate, and Bone Attachment Surface, US8603181-B2, 2013

82. T. Vanasse, G. Gupta, and J. Meridew, Medical Implant for e.g. Replacing Joint of Shoulder of Human Body During Shoulder Procedure, has Metallic Body Whose Surface is Replicated from High Resolution Scan of Bone and Promoting Bony On-Growth or In-Growth of Tissue, US2014371863-A1, 2014
83. M. Dai, Implantation Material for Surgery in Use for Repairing Bone, CN100364618-C, 2008

84. J. Tyber and C. Faresich, Osteotomy Implant of Osteotomy Implant System Used for Internal Fixation of Bone Fracture, in which Surfaces Extend in Respective Planes, US2018008419A1, 2018

85. J. Sun, Y. Han, and K. Cui, Compound Technique for Preparing Multiaperture Titanium Coating by Cold Spray and Vacuum Sintering, CN100560143-C, 2009

86. A.Z. Rosenflanz, R.P. Rusin, and J.E. Swanson, Manufacture of Dental Article or Orthodontic Appliance, e.g. Brackets, by Plasma or Thermally Spraying Particles Comprising Metal Oxide Sources on a Substrate Such that the Particles Coalesce to Form Shaped Article Comprising Aluminum Oxide, US2005136176-A1, 2005

87. C. Li, Z. Wang, L. Zhu, N. Gao, D. Hao, H. Wang, J. La, M. Guo, and H. Li, Plasma-Spray-Coated Nano Zirconia Implant has Implant Component Containing Titanium or Titanium Alloy Material Having Monolithic Structure, and Base Having Transgingival Shoulder Portion Having Uniform Coating of Nano-Zirconia, CN104042350-A, 2014

88. G.A. Walther, Implant e.g. Tooth Implant, for Implanting in Bone i.e. Jawbone, has Implant Body Inserted into Human Jawbone, and Implant Support Inserted into Body, where Area Engaged into Jawbone is Provided with Coating Made from Ceramic Material, EP2361586-A1, 2011

89. P. Jensen, Dental Device e.g. Orthodontic Archwire, has Metallic Substrate Made Of Titanium, Titanium Oxide, Nickel Titanium, Vitalium or Chrome Cobalt, Where Device is Coated with Combination of Aluminum Oxide and Zirconia, US2011183281-A1, 2011

90. T. Hotokebuchi and I. Noda, Antimicrobial Product Useful in Biological Implant e.g. Artificial Dental Root, Comprises Thermal Spraying Film Formed by High-Speed Flame Spraying Powder Having Brookite-Type Titanium Oxide on Metal, Ceramic or Plastic Substrate, JP5308754-B2, 2013

91. A. Djemai, J.J. Fouchet and J. Fouchet, Formation of Beta Phase-Titanium-Zirconium Alloy for Manufacturing e.g. Dental Implant, Involves Stacking Layers Of Metal Powders, and Selectively Fusing Powders by Concentrating Laser-Beam or Using Sintering Modular Energy Source on Layers, FR3047489A1; WO2017137671-A1, 2017

92. J. Cheng, Highly Connected Dental Structure for Dental Prostheses, has Ceramic Layer Which is Applied on the Inner and Outer Surfaces of Metal Cap Using a Plasma Spray Process, DE102011051594-A1, 2013

93. D. Wu, C. Zhining, C. Wan, and Q. Wang, IMPLANT For Bone Repair and Tooth Implant Comprises Strontium-Doped Calcium Polyphosphate Layer Coated on Surface of Matrix and Titanium Matrix, CN101927034-A, 2010

94. J.A. Sharp, Orthopedic Implant for Replacing Hip Joint with Prosthetic Joint During Replacement/Revision Hip Surgery of Patient, has Expansion Member Placed Between Portions and Adjusted by Tightening Tool to Displace Portions Relative to Each Other, WO2011156511-A3, 2011

95. R.G. Mauldin and R. Mauldin, Tubular Threaded Bone Implant for Fixation of Sacroiliac Joint e.g. for Degenerative Sacroiliitis, Has Set of Pores Defined on Body Such That Each Pore Does not Extend Through Entire Thickness of Wall of Body Between Surfaces of Body, WO2013134678-A1, 2013

96. M.A. Reiley, J. Lerman, and R.G. Mauldin, Method for Fusion of Sacral-Iliac Joint Between Iliac and Sacrum, Involves Inserting Bone Fixation Implant into Lateral Insertion Path Created Laterally Through Ilium, Sacral-Iliac Joint and Sacrum, US8986348-B2, 2015 
97. T.D. Ferro, J.R. Phillips, and A.T. Ferro, Implant Device e.g. Cementless Unicompartmental Knee Replacement Implant Device, has Tapered Protrusions Extending from Surface of Base That Mates with Bone, Where Surface of Each Protrusion Includes Surface to Increase Area for Bone Growth, US2017312084-A1, 2017

98. J.P. Ritz and C. Scott, Making Bone Implant Used for Repair of the Ends of Bones at Orthopedic Joints Involves Creating Substrate of Structurally Strong Isotropic Graphite of the Shape Desired for Bone Implant, and coating with Microporous Isotropic Pyrocarbon, US8932663-B2, 2015

99. J.R. Porter, N.A. Winslow, J. Kneisl, and J.W. Sperling, Orthopedic Implant for use in Orthopedic Surgery e.g. Shoulder Arthroplasty, has Locking Mechanism that Prevents Movement of Soft Tissue Attachment Pad with Respect to Implant, US8715356-B2, 2014

100. H. Wecker and A. Rempp, Ceramic Layer Applied to the Surface of Component by Means of a Thermal Spraying Process, Useful for Functionalization of Medical Devices, Preferably Prostheses and Implants, WO2017055270-A1, 2017

101. R.E. Brosnahan, R. Fesmire, H. Gupta, D.A. Heuer, G. Hunter, and V. Pawar, Medical Implant for e.g. hip Joint, Has Surface of Oxidized Zirconium Adapted on Portion of Femoral and Tibial Components, and Plasma Sprayed Porous Coating Applied on Portion of Surface of Oxidized Zirconium, US2006052880-A1, 2006

102. D.E. Lawrynowicz, A. Wang, and Z. Zhang, Fabrication of Medical Implant Component Involves Producing Substrate Having Bearing Surface that Articulates with Bone or Another Medical Implant, and Spraying Particles of Same or Different Material Using Thermal Type Spraying Process, US7771775B2, 2010

103. D.E. Lawrynowicz, A. Wang, and E. Jones, Providing Reactive Material on a Portion of Surface of Substrate of Medical Implant Component e.g. Femoral Stem Involves Placing Component in Holding Fixture at Atmospheric Pressure; and Spraying Material Particles at Predetermined Velocity, EP1806154-A1, 2007

104. R. Mongrain, O.F. Bertrand, S. Yue, and O. Bertrand, Intermixed Particulate Material Used in Bioresorbable stent comprises cathodic Particles Made of Cathodic Material and Anodic
Particles Made of Anodic Material Bound to Each Other, where the Materials Form a Galvanic Couple, WO2013163747-A1, 2013

105. P.A. Kramer, Preparing Medical Device e.g. Stent, Useful e.g. to Treat/Prevent Restenosis, Comprises Forming Porous Component Comprising Near Net-Shaped Device by e.g. Arc Wire Spray Process, US7854958-B2, 2010

106. J. Garcia-Forgas, P. Heinrich, H. Kreye, W. Kroemmer, A. Salito, and F.J. Garcia, Production of a Medical Implant for Joints Comprises Coating the Implant with a Particulate Material by Cold Gas Spraying, EP1864686-A1, 2007

107. R.B. Heimann, Plasma-Sprayed Hydroxylapatite-Based Coatings: Chemical, Mechanical, Microstructural, and Biomedical Properties, J. Therm. Spray Technol., 2016, 25(5), p 827-850

108. R.B. Heimann and H.D. Lehmann, Bioceramic Coatings for Medical Implants, Wiley, New Yrok, 2015

109. M. Driver, Coatings for Biomedical Applications, Woodhead Publishing Ltd, Sawston, 2012

110. Y. Dong, P. Svoboda, M. Vrbka, D. Kostal, F. Urban, J. Cizek, P. Roupcova, H. Dong, I. Krupka, and M. Hartl, Towards NearPermanent CoCrMo Prosthesis Surface by Combining MicroTexturing and Low Temperature Plasma Carburising, J. Mech. Behav. Biomed. Mater., 2015, 55, p 215-227

111. J. Cizek, V. Brozek, T. Chraska, F. Lukac, J. Medricky, R. Musalek, T. Tesar, F. Siska, Z. Antos, J. Cupera, M. Matejkova, Z. Spotz, S. Houdkova, and M. Kverka, Silver-Doped Hydroxyapatite Coatings Deposited by Suspension Plasma Spraying, J. Therm. Spray Technol., 2018. https://doi.org/10.1007/s11666018-0767-2

112. J. Cizek, I. Dlouhy, F. Siska, and K.A. Khor, Modification of Plasma-sprayed $\mathrm{TiO}_{2}$ Coatings Characteristics via Controlling the In-flight Temperature and Velocity of the Powder Particles, J. Therm. Spray Technol., 2014, 23(8), p 1339-1349

113. K. Ravi, T. Deplancke, K. Ogawa, J.-Y. Cavaillé, and O. Lame, Understanding Deposition Mechanism in Cold Sprayed Ultra High Molecular Weight Polyethylene Coatings on Metals by Isolated Particle Deposition Method, Addit Manuf, 2018, 21, p 191-200

114. C. Ning, L. Zhou, and G. Tan, Fourth-Generation Biomedical Materials, Mater. Today, 2016, 19(1), p 2-3 